\title{
Estados Unidos como una nación en desarrollo: consideraciones sobre las peculiaridades de la historia estadunidense*
}

\author{
The United States as a developing nation: \\ Revisiting the peculiarities of American history
}

Stefan Link y Noam Maggor**

\begin{abstract}
It has recently been suggested that the economic departure of the United States after the Civil War marked a "Second Great Divergence". Compared to the "First", the rise of Britain during the Industrial Revolution, this Second Great Divergence is curiously little understood: because the United States remains the template for modernization narratives, its trajectory is more easily accepted as preordained than interrogated as an unlikely historical outcome. But why should development have been problematic everywhere but in the United States? This Viewpoint argues that a robust explanation for the United States' rise is lacking: it can neither be found in an economic history literature focused on factor endowments nor in internalist Americanist historiography, which often reproduces overdetermined accounts of modernization inspired by Max Weber. The most promising avenue of inquiry, we argue, lies in asking how American political institutions configured what should properly be called an American developmental state. Such a perspective opens up a broad comparative research agenda that provincializes the United States from the perspective of development experiences elsewhere.

* Artículo recibido el 20 de abril de 2020 y aceptado el 29 de abril de 2020. Publicado originalmente como "The United States as a developing nation: Revisting the peculiarities of American history", Past E Present, 246(1), 269-306. (C) 2020, Past and Present. Los autores expresan su agradecimiento a Sven Beckert, Christine Desan, Paul Kramer, Erez Maggor, Charlie Maier, Scott Nelson, pseudoerasmus y los cinco lectores de Past and Present por su retroalimentación crítica, que inspiró y ayudó a mejorar este artículo. [Traducción del inglés de Luis Arturo Velasco Reyes.]

**Stefan Link, Dartmouth College (correo electrónico: stefan.j.link@dartmouth.edu). Noam Maggor, Queen Mary University of London (correo electrónico: maggor1@gmail.com).
\end{abstract}


Keywords: United States; developmental state; liberalism; Dutch disease; industrialization; Great Divergence.

\section{ReSUMEN}

Recientemente, se ha sugerido que la partida económica de los Estados Unidos después de la Guerra Civil marcó una "segunda Gran Divergencia”. En comparación con la "primera” - el surgimiento de Gran Bretaña durante la Revolución industrial-, esta segunda Gran Divergencia es curiosamente poco entendida: debido a que los Estados Unidos siguen siendo la plantilla para las narrativas de modernización, su trayectoria es más fácilmente aceptada como preordenada que interrogada como un resultado histórico poco probable. Pero ¿por qué el desarrollo debería haber sido problemático en todas partes, excepto en los Estados Unidos? Este artículo argumenta que falta una explicación sólida para el ascenso de los Estados Unidos: no se puede encontrar en una literatura de historia económica centrada en las dotaciones de factores ni en la historiografía americanista internalista, que a menudo reproduce relatos de modernización sobredeterminados inspirados por Max Weber. La vía de investigación más prometedora, argumentamos, es preguntar cómo las instituciones políticas estadunidenses configuraron lo que debería llamarse adecuadamente un Estado de desarrollo estadunidense. Tal perspectiva abre una amplia agenda de investigación comparativa que provincializa a los Estados Unidos desde la perspectiva de las experiencias de desarrollo en otros lugares.

Palabras clave: Estados Unidos; Estado desarrollista; liberalismo; síndrome holandés; industrialización; Gran Divergencia.

Entre 1850 y 1950 los Estados Unidos transformaron decisivamente su lugar en el orden económico mundial. En 1850 este país era fundamentalmente un exportador de algodón producido por esclavos para una Europa en proceso de industrialización. El crecimiento de la economía estadunidense permaneció enclavado en modelos consolidados del comercio atlántico. Cien años después el país se había transformado en el líder industrial indiscutible y en el proveedor hegemónico de capital del mundo. Tras emerger victorioso de la segunda Guerra Mundial, los Estados Unidos habían desplazado a Gran Bretaña como la potencia predominante - más aún que 
su contendiente en la Guerra Fría - para imprimir su visión de una economía política global en el mundo. Si la Revolución industrial en Gran Bretaña a finales del siglo xviı marcó el inicio de una "Gran Divergencia” (Pomeranz, 2001) de "Occidente" respecto de otras regiones del mundo, el dominio estadunidense en las últimas décadas del siglo xix y las primeras del xx marcó una “segunda Gran Divergencia” (Beckert, 2017) que impuso a los Estados Unidos como el líder industrial y la potencia imperial del mundo.

El triunfo de los Estados Unidos ha ocultado cuán peculiar ha sido realmente esta trayectoria. El país no sólo superó su estatus de exportador periférico de cultivos comerciales, también logró desafiar la división global de trabajo que respaldaba el orden liberal-imperial del mundo a finales del siglo xIX y principios del Xx. La "Gran Especialización” (Findlay y O’Rourke, 2007) de aquella era, moldeada por el imperialismo europeo y británico particularmente, dividió el mundo en exportadores de materias primas y productos primarios, por un lado, y exportadores de productos manufacturados, por el otro. Conforme a esta división del trabajo, el núcleo industrial, principalmente en Europa Occidental, se inclinó con mayor intensidad hacia la industria manufacturera, que extraía materias primas y productos agrícolas de otros países en todo el mundo. Estos países, a su vez, exportaban productos primarios a cambio de productos manufacturados de Europa. Sin embargo, la trayectoria de los Estados Unidos se mantuvo al margen de esta división. Sin ser núcleo ni periferia, este país exportaba un flujo siempre creciente de materias primas y productos agrícolas mientras se industrializaba rápidamente. Para la primera Guerra Mundial, esta antigua república esclavista, productora de algodón, se había convertido en un gran exportador de productos manufacturados. ${ }^{1}$

¿Cómo pudieron los Estados Unidos, a diferencia de las periferias, romper la rigurosa geografía de especialización que caracterizaba la economía mundial antes de la primera Guerra Mundial? Si se consideran las diversas literaturas sobre la historia económica global, la historia de los Estados

\footnotetext{
1 "Sin embargo, a grandes rasgos, no es incorrecto concebir el comercio mundial en el siglo xIx en términos de Norte-Sur, con el Norte rico e industrializado exportando productos industriales a cambio de las exportaciones primarias de un Sur pobre y rural [...] El mayor problema respecto de esta simple caracterización fue que el Nuevo Mundo era rico y cada vez más industrial, pero también principalmente exportador de productos primarios" (Findlay y O’Rourke, 2007: 413-314). Vaya problema. La reciente contribución de O’Rourke y Williamson (2017) al debate sobre la industrialización en la periferia produce un corto circuito en el análisis de los Estados Unidos al clasificarlo simplemente como un país "núcleo".
} 
Unidos a finales del siglo xIx y principios del siglo xx, y la historia del capitalismo en dicho país, nos vemos tentados a concluir que esta cuestión aún no se ha formulado adecuadamente, a pesar de que se ha respondido de manera convincente. En retrospectiva, la historia de los Estados Unidos parecía demasiado necesaria y familiar, por lo que inspiró la tendencia a narrarla, en lugar de investigarla como un proceso altamente improbable. En efecto, la escasez relativa de reflexión académica sobre los fundamentos económicos del dominio de los Estados Unidos es, en sí misma, una evidencia de la aceptación general de este proceso como un asunto poco problemático. El crecimiento de Europa Occidental, y particularmente del Reino Unido, ha interesado a académicos por décadas, y la búsqueda de estas causas ha inspirado una literatura colosal, así como debates enardecidos (sin resolver). ${ }^{2}$ Mientras tanto, la hegemonía industrial de los Estados Unidos del siglo xx parece haber generado interés sólo en tiempos recientes, y no es coincidencia que ocurra ahora que el poder de los Estados Unidos ya no parece inexpugnable. ${ }^{3}$

Enfatizar la naturaleza atípica de la historia de los Estados Unidos difícilmente revive la idea del excepcionalismo estadunidense. Más bien, lo contrario. Se trata, pues, de derribar uno de los dogmas fundamentales del pensamiento excepcionalista y reiterar que los Estados Unidos, en realidad, no estuvieron fuera de las "tendencias universales de la historia, el destino 'normal' de las naciones” (Rodgers, 1998: 23; Tyrrell, 1991; Allen, 2014). Nos parece plausible asumir, en cambio, que el lastre gravitacional de las restricciones político-económicas estuvo presente en los Estados Unidos, al igual que en cualquier otro lugar, y que, por ello, deben tomarse rigurosamente en cuenta los resultados divergentes. Para esto, es necesario situar este país en una historia de desarrollo comparativa que no se base en referentes analíticos derivados de la experiencia estadunidense. Lo anterior implica reconocer la economía esclavista como el punto de partida del capitalismo estadunidense, similar al de otras colonias del Nuevo Mundo;

\footnotetext{
${ }^{2}$ Véanse, por ejemplo, Williams (1944), Rostow (1960), Landes (1969 y 1998), Hobsbawm (1968), Wallerstein (1974), Aston y Philpin (1985), North y Weingast (1989), Mokyr (1993 y 2017), Findlay y O’Rourke (2007), Arrighi (2010), Ferguson (2011) y Beckert (2014).

${ }^{3}$ El surgimiento de los Estados Unidos como una nación industrial por sus propios méritos es un punto central en Hopkins (2018: capítulo 7 en partícular). Para un análisis novedoso de los fundamentos económicos del poder de los Estados Unidos, véanse Kramer (2011), Beckert (2017) y Black (2018). De forma similar, la primera Gran Divergencia ameritó un mayor escrutinio conforme la hegemonía mundial británica disminuía y, con ello, la historia whig británica perdió su poder persuasivo.
} 
oponerse a una literatura que ha visto la industrialización - una meta terriblemente elusiva en toda la periferia global - como una fuerza irresistible en el caso de los Estados Unidos, como un proceso abrumador que la corrupción gubernamental, la ineptitud empresarial, la crisis económica, la resistencia colectiva y las diferencias ideológicas no habrían podido detener. Nuestro objetivo es provincializar el desarrollo de los Estados Unidos desde la perspectiva de una experiencia histórica exterior, para tratarlo como un camino entre muchos y no como el patrón analítico para todos. ${ }^{4}$

La tarea de reconsiderar la "segunda Gran Divergencia” de los Estados Unidos parece ser particularmente apremiante hoy en día, dado que el estudio histórico del cambio económico atraviesa lo que podríamos llamar un cambio de paradigma pospolanyiano. Por un lado, los éxitos del capitalismo manejado por el Estado en Asia Oriental, más recientemente en China, han puesto en duda los axiomas del mercado del Consenso de Washington. Desde una perspectiva histórica comparativa más amplia, parece evidente que el crecimiento coordinado por el Estado ha sido la regla y no la excepción (Chang, 2002). Esto ha llevado a cuestionarse por qué los Estados Unidos, con sus instituciones gubernamentales supuestamente no intervencionistas, pudieron haber adoptado esta norma desde un principio. Por otro lado, hay una consciencia cada vez mayor de que los llamados mercados “libres” son unicornios históricos: no existen. Todas las economías se designan políticamente, son gobernadas institucionalmente y están incrustadas socialmente, incluyendo las que son a fortiori (neo)liberales. ${ }^{5}$ Todas las instituciones económicas son políticas, resultan de la competencia y del compromiso políticos y permanecen sujetas a éstos. En la actualidad, las antiguas dicotomías de suma cero entre mercados y planificación, entre la "intervención” del Estado y la actividad “espontánea” del mercado, generalmente se consideran deficientes. Estas observaciones exigen darle una nueva mirada a

\footnotetext{
${ }^{4}$ Para una perspectiva similar, véase Crossley (2020).

${ }^{5}$ Éste fue, por supuesto, el tema central de Polanyi (2001). Para trabajos más recientes en esta misma línea, véanse Ogle (2017), Slobodian (2018), Krippner (2017), Vogel (2018), Mazzucato (2013) y Desan (2014). En palabras de Slobodian, este enfoque identifica el neoliberalismo como "un conjunto de ideas y un modo de gobierno entre otros - como una forma o variedad de la regulación más que su radicalmente Otro-". Nótese que esta perspectiva es diferente a la del institucionalismo de North, que privilegia a ciertas instituciones (imperio de la ley, derechos de propiedad, gobierno limitado) como las "correctas" (es decir, que inducen el crecimiento). La perspectiva de North es, por lo tanto, implícitamente normativa y prescriptiva, por lo que haríamos énfasis en que todas las organizaciones institucionales implican disyuntivas y, por ende, son causa y efecto de contestaciones políticas. Al igual que los mercados "libres", las instituciones "ideales" son expresiones ideológicas más que herramientas analíticas.
} 
la arquitectura política de la industrialización estadunidense. ¿Cómo hicieron las instituciones del Estado para forjar, movilizar y controlar los mercados? ¿Cómo fue que actores políticos, alineamientos sociales y políticas contrapuestas condujeron a un cambio institucional?

Con estas preguntas en mente, hemos formulado puntos de partida conceptuales para limitar nuestra investigación. Recurrimos a la literatura previa para conseguir respuestas y formular algunas hipótesis preliminares. Posteriormente, analizamos en este orden: 1) las historias económicas globales, especialmente las concentradas en cuestiones de desarrollo comparativo con énfasis en el comercio y en la "dotación de factores" (territorio, recursos, población, geografía, etc.); 2) la historiografía americanista desde la Guerra Fría, y 3) las tentativas más recientes, tanto en historiadores como en científicos sociales, por entender el Estado estadunidense. En el proceso, encontramos aliados en lugares inesperados, por ejemplo, en la sociología comparada sobre la economía política y en la literatura de Estados desarrollistas del este asiático. Anticipemos nuestras conclusiones: tanto las fortalezas como los defectos de las opiniones ya existentes se originan en un conjunto de tendencias analíticas en el que convergen diversas escuelas, concretamente, un exceso de confianza en los patrones de modernización, a expensas de un análisis político incisivo de las instituciones. Nos oponemos al punto de vista tradicional sobre los Estados Unidos como una sociedad mercantil y hacemos hincapié en un amplio rango de políticas intervencionistas entrelazadas - aunque usualmente descoordinadas - que surgen de las instituciones del Estado estadunidense en diferentes escalas geográficas. Estas políticas, diseñadas en el terreno disputado de la política, se aunaron a lo que podríamos denominar un Estado desarrollista estadunidense: un Estado cuyas instituciones ejercieron la disciplina colectivamente sobre actores económicos e impulsaron la reorientación del capitalismo estadunidense de la exportación agraria a la industrialización interna.

\section{I. ¿DOTACIÓN DE FACTORES?}

La literatura comparativa reciente sobre el desarrollo global desde el siglo XIX destaca con rigor la trayectoria inusual de los Estados Unidos y muestra que, a pesar de los patrones clave que tuvieron muchos países análogos en el mundo, esta nación emergió en forma única. Los Estados Unidos participa- 
ron notablemente en un patrón extendido durante finales del siglo xix que consistía en la penetración en territorios aledaños. Durante este periodo se expandió hacia una "Gran Frontera”, y las Grandes Llanuras se alzaron junto con las praderas canadienses, las pampas argentinas, el altiplano sudafricano, las estepas de Asia Central y los campos australianos. Al igual que estas regiones económicas de rápida expansión, los Estados Unidos conquistaron territorios violentamente, absorbieron grandes cantidades de capital europeo y atrajeron a un gran número de inmigrantes, lo que facilitó la producción agrícola masiva que fluyó en los mercados mundiales. ${ }^{6}$ Junto con su frontera "horizontal" extensiva, los Estados Unidos también desarrollaron una frontera "vertical" robusta. Como en algunas regiones periféricas de la economía mundial durante el apogeo de la "geología imperial”, los estadunidenses excavaron combustibles fósiles, metales y minerales a ritmos acelerados. Consecuentemente, este país se convirtió en el centro de extracción intensiva de la riqueza de la tierra, incluyendo cobre (junto con México, Chile, Perú y Congo), carbón (con Rusia, India y China), estaño (con Malasia, Indonesia y Bolivia), plata (con México y Australia), oro (con Australia y Rusia), plomo (con Australia), zinc (con Australia) y petróleo (con Rusia) (Osterhammel, 2014: 655-656 y 658-659).

Las fronteras horizontales y verticales de los Estados Unidos excedieron por mucho las de otras regiones del mundo tanto en dimensión como en diversidad. Esta abundancia de recursos se debía no sólo a la mejor dotación natural, sino también a métodos más intensivos y extensivos de exploración, cultivo y extracción promovidos por las instituciones estadunidenses. La capacidad para hacer esto, por supuesto, es parte del acertijo histórico (David y Wright, 1997). Sin embargo, es aún más destacable que la expansión fronteriza no desencadenó una industrialización a gran escala en ningún otro lugar en el mundo salvo en los Estados Unidos, y mucho menos una amplia transformación económica. La abundancia de recursos en otros lugares generalmente se convirtió en una "maldición” que condujo a un "síndrome holandés” - especialización excesiva en la extracción o en el cultivo de productos primarios - y, consecuentemente, a un fracaso en la industrialización (Sachs y Warner, 2001).? Las economías de Argentina, Australia, Chile, Brasil

\footnotetext{
${ }^{6}$ La inversión extranjera alcanzó $20 \%$ del рів mundial en la víspera de la primera Guerra Mundial, una cifra que sólo se repetiría alrededor de 1980 (Findlay y O’Rourke, 2007: 408).

${ }^{7}$ Por supuesto, estamos muy conscientes de la normatividad en la que se funda el lenguaje en este caso: "fracaso", "maldición”, "sobreespecializado", “mal”, etc. Al provincializar la historia de los Estados Unidos, se emprendería un largo camino para lograr deshacerse de estas suposiciones.
} 
y Rusia, sólo para mencionar algunas, crecieron muy rápido debido a su exportación de productos primarios, pero su desarrollo industrial continuó siendo comparativamente limitado. ${ }^{8}$ La industria local en estos países se limitaba al procesamiento de alimentos y otras materias primas, y no a una amplia gama de productos manufacturados para consumo interno y mucho menos externo (Findlay y O’Rourke, 2007: 411). ${ }^{9}$ En contraste, los Estados Unidos aprovecharon la expansión de sus fronteras y de sus industrias extractivas para desarrollar lo que para tiempos de la primera Guerra Mundial sería la economía manufacturera más grande del mundo (Wright, 1990; David y Wright, 1997; Wright y Czelusta, 2004).

Leer opiniones que se oponen a la disparidad entre los Estados Unidos y algunas periferias en el mundo equivale a encontrar una literatura plagada con elisiones sutiles, argumentos circulares, lógicas cambiantes y aseveraciones contradictorias. Los académicos atribuyen comúnmente el desarrollo industrial del país a factores que, páginas más tarde, utilizan para explicar los fracasos en la industrialización en otros países. Se limitan a asumir que existen precondiciones cruciales, pero no las analizan. Se sirven de los mismos bloques que utilizan los historiadores para narrar la deslumbrante llegada de la modernidad estadunidense, pero con un cambio abrupto en la música de fondo para mostrar una fatalidad inminente en otros contextos.

Pensemos, por ejemplo, en cómo la literatura trata el problema del tamaño del mercado doméstico de cada país. A veces, un mercado doméstico pequeño se considera la razón del fracaso de la industrialización de un país; en otras ocasiones, se muestra como una consecuencia de este fracaso. A veces, un mercado doméstico grande se presenta simplemente como un hecho geográfico y demográfico afortunado. Otras veces, un mercado doméstico grande se muestra como un proyecto social y político. El economista Edward Barbier, por ejemplo, en lo que por lo demás es una síntesis bien lograda, explica en un típico hilo de non sequituors que el "tamaño pequeño de la economía” de Nueva Zelanda "limitó su diversificación más allá de las principales industrias agrícolas”. Argentina, al contrario, no era

\footnotetext{
${ }^{8}$ En Rusia, las continuas expansiones territoriales llevaron a que, a finales del siglo xix, más de 60\% de la riqueza nacional se encontrara en sus tierras de cultivo, una cifra mayor a la de la India en ese entonces (53.8\%). En los Estados Unidos, a pesar de la expansión territorial masiva, la cifra se mantuvo en $19.2 \%$ (Barbier, 2011: 390).

${ }^{9}$ O'Rourke y Williamson (2017: 2) distinguen con pertinencia entre el procesamiento de materias primas, principalmente para exportaciones, que es más propio de la periferia, y la producción de "productos que compiten en la importación y exportación”.
} 
pequeña en ningún sentido; aun así tuvo "muy poca industria doméstica”, por lo que no logró generar una demanda efectiva de extracción de recursos. Finalmente, Australia tuvo también un territorio grande y un mercado doméstico pequeño, pero vio crecer sus industrias extractivas. No obstante, estos sectores de extracción no desarrollaron "nexos con ninguna industria doméstica” y, por lo tanto, generaron "pocos esfuerzos por diversificar la economía” (Barbier, 2011: 408, 410 y 411). En el caso de los Estados Unidos, en cambio, Barbier (y otros) advierte con seguridad la presencia de óptimos "nexos y complementariedades de la dotación de recursos" que le permitieron al país usar sus riquezas naturales para impulsar su industrialización (Findlay y O’Rourke, 2007: 411). Sostiene que es un hecho que un "enorme mercado doméstico” preexistente apoyó tanto la extracción intensificada como la capacidad creciente de la industria manufacturera, al tiempo que se mantenía la capacidad de exportación. ${ }^{10}$

La importancia de los costos de los envíos transatlánticos es otro ejemplo de la inestable causalidad que enfrentamos al explicar la industrialización estadunidense. En su gran descripción del comercio y el desarrollo globales, Ronald Findlay y Kevin O’Rourke (2007) afirman que los Estados Unidos se beneficiaron con los altos costos de transportación de minerales como el hierro. En lugar de comerciar a nivel internacional, esos minerales estimularon la industria nacional. A diferencia del algodón en bruto, que era transportado con facilidad a través del Atlántico, el alto costo de transportación de minerales pesados "atrajo una industria manufacturera interna más que desplazarla”. No obstante, admiten enseguida que éste "no es el caso en Latinoamérica [...] cuyas exportaciones”-a pesar de que, según nuestras suposiciones, sus costos de transportación fueran igualmente altos - "consistían principalmente en productos primarios”, incluyendo, por supuesto, muchos minerales industriales importantes. Barbier sigue una línea similar cuando celebra la habilidad de los Estados Unidos para florecer debido a su "distancia económica" respecto del resto del mundo. El aislamiento virtual de la economía estadunidense - la sentencia de muerte del desarrollo en el resto del mundo - le permitió alimentar el comercio interno y la expansión

${ }^{10}$ Alfred Chandler (1994: 51-52) identificó en forma similar “el tamaño geográfico y el rápido crecimiento del mercado doméstico [estadunidense]” como un elemento clave en la industrialización de los Estados Unidos, pero sin explicar realmente cómo ocurrió o cómo creció tan rápido. Richard Bensel (2000) pertinentemente centró su atención crítica en el tamaño geográfico del mercado, en sus limitaciones y en su coherencia interna como elementos determinados políticamente. 
industrial. En los países de Latinoamérica, sin embargo, Barbier deja en claro que los costos "prohibitivos" de transportación no atrajeron prácticamente nada, sino que, en vez de eso, suprimieron los incentivos para la exploración. De igual modo, en lugares como Sudáfrica y Australia, "los formidables costos de transportación” y la distancia “de las principales rutas comerciales internacionales” a los principales mercados europeos no fungían como un estímulo a la industrialización doméstica, sino como un impedimento para una extracción de minerales más intensiva (Findlay y O’Rourke, 2007: 420; Barbier, 2011: 409, 427-428).

El hecho de que el análisis de “dotación de factores” genere más preguntas que respuestas se puede ilustrar de otra forma: con la consideración de recurrir a una comparación de país a país. El caso de la Belle Époque de Argentina, de 1875 a 1913, es elocuente, especialmente porque reprodujo en muchas maneras la experiencia de los Estados Unidos (los académicos de Latinoamérica están mucho más conscientes de esto que el otro país). En aquella época, un recién consolidado Estado argentino había superado una serie de crisis constitucionales y se había afirmado en sus zonas fronterizas. Tras lanzar su infame Campaña del Desierto, diezmó y reubicó con violencia a la población nativa, estableciendo con mayor firmeza una soberanía nacional en las periferias más lejanas de su territorio. El fácil acceso a reservas de tierra fértil cada vez mayores - de 400000 a 858000 kilómetros cuadrados tan sólo entre 1867 y 1890 - impulsó el crecimiento de una vibrante economía de exportación de recursos agrícolas y pastizales dentro de los límites del cono sur. Enormes entradas de capital extranjero financiaron la expansión masiva del sistema de ferrocarril, lo que facilitó la entrada de habitantes. La agricultura de granos - trigo, maíz y linaza - despegó, junto con la crianza de ganado vacuno y bovino. En consecuencia, la región superó sus orígenes como satélite de la economía extractiva de los Andes Centrales, que había sido la fuente de riqueza de la región. ${ }^{11}$

Argentina se convirtió en el principal modelo de política económica liberal durante este periodo. Se comprometió con firmeza a proteger sus dere-

\footnotetext{
${ }^{11}$ Argentina era el país más rico de Latinoamérica en esa época, pero resultó en una "gran decepción" en términos de industrialización, con niveles de actividad manufacturera per cápita menores a los de los países europeos con menor ingreso per cápita (véase Bulmer-Thomas, 2014: 154). Para más información sobre Argentina, véanse Paolera y Taylor (2003: 235-237), Lewis (1983) y Elena (2016). Para más información sobre el compromiso compartido por la delimitación de fronteras y la expansión ferroviaria en los Estados Unidos y en Argentina, y sobre el choque provocado por la resistencia de los pueblos indígenas, véase Maier (2016: 139-145, 204 y 207).
} 
chos de propiedad (para los colonos), el comercio global, la inmigración abierta, un gobierno no intervencionista y el patrón oro. La élite nacional, conformada por comerciantes y productores de exportaciones, adquirió más confianza y adoptó un espíritu de mejora con vistas al futuro. Promovió con agresividad la agricultura científica, criando ovejas y ganado con el fin de maximizar la producción de carne y satisfacer mejor la demanda de los consumidores. Como resultado, la economía de Argentina generó notables tasas de crecimiento. Siendo el umbral a los ricos pastizales de las pampas, la ciudad de Buenos Aires creció a un ritmo acelerado y pasó de ser un pequeño pueblo provincial a una metrópolis con más de 1.5 millones de habitantes a inicios de la primera Guerra Mundial, la ciudad más grande de Latinoamérica y la segunda más grande en el litoral del Atlántico, tan sólo superada por Nueva York. Los puertos de la capital argentina, sus patios de maniobras ferroviarias y sus bodegas conectaron los flujos de materias primas desde una periferia que crecía rápidamente hasta los consumidores en mercados urbanos industriales en Europa. Se originó un sector local de industria manufacturera basado en el procesamiento de alimentos. Con todo esto, entre 1880 y 1914 el PIB per cápita de Argentina aumentó en un promedio anual de $3.3 \%$, un ritmo que superaba el de Gran Bretaña (1\%), Canadá $(2.2 \%)$ e incluso el de los Estados Unidos $(2.1 \%) .{ }^{12}$

Lo impactante de este ejemplo, visto desde la perspectiva de la historiografía de los Estados Unidos, es su gran semejanza con las “explicaciones” frecuentes de la industrialización estadunidense durante el mismo periodo: una frontera en expansión, la limpieza étnica de los pueblos indígenas, la expansión masiva de las redes ferroviarias hacia el interior del continente, el rápido establecimiento de colonos europeos, el crecimiento de un panorama agrícola comercial que produjo increíbles volúmenes de productos primarios del mercado, una gran inversión en agricultura científica y en otras tecnologías, y, finalmente, el crecimiento de centros urbanos orientados a la recolección, el procesamiento y la distribución de esta riqueza natural. Sólo por mencionar un ejemplo obvio, Nature's Metropolis, la obra canónica de William Cronon, atribuye el rápido crecimiento de Chicago precisamente a su posición como puerta de entrada a un flujo incesante de materias primas, como trigo, carne y leña (Cronon, 1991). Dejando de lado la melancolía de

\footnotetext{
${ }^{12}$ Existen algunos desacuerdos en lo que concierne a las cifras precisas, pero ninguna opinión rechaza la tendencia general (Cortés Conde, 2000: 267).
} 
Cronon respecto de esta expansión económica (hablaremos de esto más adelante), su trabajo se basa sobre todo en explicar el "éxito" en el desarrollo a través de estos factores. En el caso de Argentina, sin embargo, los académicos interpretan los mismos procesos como una bendición económica muy contradictoria, e incluso como un presagio de un siglo de crisis y declive.

En contraste con la literatura sobre el oeste americano, los estudiosos argentinos sobre Buenos Aires y las pampas han visto un crecimiento basado en la exportación y "predominantemente en la agricultura” no como señal de un desarrollo capitalista en marcha, sino como causa de gran preocupación (Barbier, 2011: 406).$^{13}$ El énfasis de la capital argentina en el procesamiento de carne, molienda de harina y lavado de lana, junto con otros productos de consumo como cuero, artículos de madera y vidrio, generó apenas una estrecha base para la industria manufacturera. Al menos desde la década de los treinta, varias generaciones de académicos en Argentina han tratado de dilucidar "qué salió mal" - un marco problemático, ciertamente-. Han analizado el "malestar" estructural severo causado por el crecimiento basado en la exportación, lo cual llevó al país a dificultades endémicas con la balanza de pagos, con crisis de deuda pública y con inestabilidad política y social. ${ }^{14}$ En otras palabras, Cronon y otros académicos americanistas daban por sentado que un camino seguro a un milagro económico era a menudo - en caso de no haber otros factores o fuerzas no especificados - el camino a la dependencia y a la crisis. ${ }^{15}$ En tiempos más

${ }^{13}$ Para un buen resumen sobre estas discusiones en el contexto de Latinoamérica, sobre todo de Argentina, véase Brown (2008). Véase también, más recientemente, un número especial sobre "excepcionalismo argentino" en Latin American Economic Review: Glaeser, Di Tella y Llach (2008) y Campante y Glaeser (2018).

${ }^{14}$ Hacia 1900 la producción de la industria manufacturera era tan sólo $15 \%$ del pIB y mantuvo una estrecha relación con el sector de exportación. Los productos alimenticios, las bebidas y el tabaco conformaron $56.5 \%$ de la industria manufacturera argentina. Otros productos secundarios - cuero, productos de madera, piedra, vidrio y cerámicas - conformaron $18.8 \%$; véase Reynolds (1985: 88). Para estudios que revisan la industrialización de argentina, además de aquellos que sólo pueden atenuar parcialmente descubrimientos anteriores, véanse Rocchi (2006) y Pineda (2009).

${ }^{15} \mathrm{El}$ estudio reciente de Campante y Glaeser (2018) confirma nuestra idea de que Chicago y Buenos Aires eran ciudades similares en el siglo xix, principalmente como núcleos ferroviarios hacia periferias continentales y como puertas de entrada para el flujo masivo de grano y carne. Chicago era conocida, económicamente, por su habilidad para alimentar una amplia base industrial y convertirse en una ciudad industrial, además de ser un centro de comercio y de procesamiento de alimentos. Su análisis hace hincapié particularmente en el alto índice de empleo de Chicago en un avanzado sector de productos de fundición y de maquinaria, con el que pudo abastecer a una población del cercano oriente conformada por campesinos relativamente adinerados, lo que distinguió a Chicago de Buenos Aires (esto tiene poca importancia en el trabajo de Cronon). Concluimos que el análisis de Cronon sobre Chicago puede apli- 
recientes, en su magistral exploración de la primera década de 1800 a nivel global, Jürgen Osterhammel reconoce el problema: “¿Por qué los países de Latinoamérica no tuvieron éxito conectándose con la dinámica industrial [...] ante los experimentos con la sustitución de importaciones patrocinada por el Estado durante el periodo entreguerras? Ésta sigue siendo una pregunta sin respuesta” (2014: 660). ${ }^{16}$ Si éste es el caso, debemos admitir que la razón por la cual los Estados Unidos sí tuvieron éxito sigue sin estar clara.

\section{LOS TRES MODELOS WEBERIANOS DE LA HISTORIA ESTADUNIDENSE}

Las historias de los Estados Unidos durante la Edad de Oro y la era progresista han estudiado el crecimiento de dicho país desde la perspectiva de parámetros históricos nacionales, sin plantearse explícitamente comparaciones globales. Académicos como Alfred Chandler, Louis Galambos y Robert Wiebe - un grupo al que podríamos llamar historiadores whig estadunidenses - recurrieron a una diversidad de ciones (industrialización, urbanización, profesionalización) para narrar el auge de un capitalismo estadunidense más eficiente, racional y moderno (Chandler, 1977; Galambos, 1970; Wiebe, 1967)..$^{17}$ Sus trabajos describen el periodo entre la Guerra Civil y la Gran Depresión como una transformación social, política y económica a la vez vasta y progresiva. Los mercados competitivos de pequeños propietarios cedieron ante el capitalismo gerencial, las industrias de producción en masa eliminaron las ya obsoletas distinciones entre oficios, las economías locales se integraron en un mercado nacional, una administración federal de gran capacidad remplazó un Estado arcaico de "cortes y partidos", el progresismo y el New Deal eclipsaron al populismo. Estos académicos no sólo percibieron que el proceso era generalmente bienvenido, sino que también, y de manera más significativa, lo consideraron inevitable. Cuando esta literatura se planteaba un enfoque comparativo, asumía el excepcionalismo

carse mucho mejor a Buenos Aires. Para saber más sobre la base industrial diversa de Chicago, véase Lewis (2008).

${ }^{16}$ Para otro trabajo maravilloso, véase Topik y Wells (2014), quienes dedican mucha atención a la continua heterogeneidad en la economía mundial interconectada, pero no ahondan en el caso de los Estados Unidos.

${ }^{17}$ Wiebe es mucho menos optimista respecto de este proceso. Véanse las reflexiones esclarecedoras de Sklar (1992) sobre cómo el pensamiento de la modernización permeó la historiografía estadunidense en la forma de un "positivismo evolutivo". 
estadunidense. Cuando recurría a una teoría del desarrollo, ésta era la de la modernización. Desprovisto de su contingencia histórica y asociado con el progreso histórico, el desarrollo estadunidense podía identificarse con la modernización misma. El resultado fue una tautología profunda: los Estados Unidos se modernizaron más exitosamente, por ponerlo de algún modo, porque se volvieron más exitosamente modernos.

Por supuesto, el triunfalismo más o menos tácito de los whigs estadunidenses nunca se hizo público a nivel mundial. Los escépticos de diferentes índoles han desarrollado modelos opuestos teóricos y narrativos, de los cuales dos son destacables. La melancolía podría considerarse un modelo alternativo. Más que celebrar la modernización de los Estados Unidos, estas historias han hecho hincapié en sus efectos nocivos. El proceso restó poder a los trabajadores y aseguró el triunfo del capital (Montgomery, 1987; Fink, 1976; Gutman, 1976). ${ }^{18}$ Mercantilizó y devastó el medio ambiente (Cronon, 1991). Imposibilitó otras alternativas políticas democráticas (Goodwyn, 1976). Otro modelo alternativo, que podríamos llamar normativo, ha desafiado la creencia whig sobre la eficiencia y la racionalización crecientes. Este modelo encuentra poca racionalidad en la transformación de los Estados Unidos y ninguna búsqueda de orden. Al contrario, hace énfasis en la trampa, el desperdicio, la manipulación y la corrupción (Josephson, 1934; Hofstadter, 1948; White, 2011).

Estos tres modelos explicativos - el whig, el melancólico y el normativo - ciertamente no agotan la historiografía, pero sí representan patrones que la impregnan. ¿Qué poder explicativo tienen estos modelos para la cuestión del desarrollo estadunidense? Los escépticos han señalado - de manera correcta, según nuestro punto de vista - que los whigs introdujeron ciegamente una equivalencia weberiana entre modernidad capitalista y racionalización, dando a luz, por lo tanto, a una obra optimista, poco convincente y sobredeterminada sobre las transformaciones de los Estados Unidos durante el siglo xix. Pero los escépticos protestan demasiado. Los modelos melancólico y normativo no son completamente opuestos a la narrativa whig, como negativos fotográficos. A pesar de las diferencias en su temperamento, reproducen los contornos de la misma narrativa de la modernización que se proponen criticar.

\footnotetext{
${ }^{18}$ Para una crítica de la tendencia de la historia laboral a asimilar las suposiciones sobre la modernización, véase Rodgers (1977).
} 
El modelo melancólico echa atrás los juicios de valor de la narrativa whig, pero, esencialmente, deja sus contornos intactos. Por ejemplo, pocos lectores podrían confundir el profundo sentido de remordimiento que permea la historia de Chicago de Cronon - su lamento por la pérdida de la autonomía individual, la degradación del medio ambiente, la erradicación de las culturas indígenas - con el triunfalismo de la obra de Chandler. Sin embargo, en su interpretación económica, Cronon sigue por completo la línea de Chandler. De forma semejante a los gerentes weberianos de Chandler, los capitalistas de Cronon "predican ante el altar de la eficiencia” e hicieron una "guerra contra el desperdicio" mientras administraban el flujo incesante de ganado, leña y grano. Al igual que Chandler, Cronon enfatiza el papel decisivo de la tecnología, especialmente el ferrocarril y el telégrafo (junto con otros inventos más triviales como los elevadores de granos, los automóviles refrigerados, los alambres de púas y las segadoras McCormick). Cronon concede que "ningún historiador ha profundizado más" en las fuerzas económicas detrás de este proceso que el propio Chandler (Cronon, 1991: 410, véanse también 442 y 458). Al considerar irrelevante la oposición política al poder corporativo a finales del siglo xix, defiende que la consolidación corporativa, en términos de Chandler, estaba regida por una "lógica de capital” profundamente arraigada - y, por lo tanto, más allá del alcance de la protesta social y de la influencia política-(Cronon, 1991: 139). ${ }^{19}$

Si bien el modelo melancólico comparte con los whigs un sentido de inevitabilidad, el tercer modelo, el normativo, narra los eventos en contra del implícito contrafactual de una alternativa preferible. Es decir, introduce la modernización por la puerta trasera. Aquí, la historia de los Estados Unidos se considera deficiente en ciertos referentes - a menudo no completamente articulados-. Un desarrollo más ordenado, equitativo y benigno podría haberse dado si los capitalistas de los Estados Unidos no hubiesen sido tan imprudentes, si el Estado estadunidense fuese más capaz, burocrático e inmune a la corrupción, si los trabajadores y los campesinos no hubiesen sido cautivados por mitologías de mercado generalizadas. Richard White, por ejemplo, en su obra Railroaded, ha buscado distanciarse de

\footnotetext{
${ }^{19}$ Cronon, por ejemplo, asevera que la revuelta política de granjeros reflejó la falta de entendimiento en lo que respecta a los imperativos económicos "estructurales" que fundaron "el sistema de mercadeo de grano a escala masiva”. La obra converge con la opinión de Chandler sobre que el auge del capitalismo gerencial fue estrictamente un "fenómeno económico" y, por ende, inmune a la política; véase Chandler (1977: 497).
} 
Wiebe y Chandler, a los que identifica como "hijos de Max Weber” y de quienes rechaza la equivalencia entre la modernidad "y un orden impuesto por organizaciones impersonales a gran escala” (White, 2011: xxx-xxxi). La descripción que ofrece Railroaded sobre la modernidad capitalista, no obstante, no es muy diferente, sino que es más bien la imagen de los whigs a la inversa: en lugar de ser racional, eficiente y productiva, es volátil, caótica y derrochadora. Lejos de los mandarines sobrios e imparciales, sus capitalistas son corruptos, ineptos y tacaños. El Estado no está habitado por burócratas diligentes, sino por políticos que buscan su propio beneficio. $\mathrm{La}$ funcionalidad se ve remplazada con la disfuncionalidad, el orden con el desorden, el cumplimiento con el fracaso. Esta historiografía normativa preserva implícitamente el paradigma de Chandler como punto obligado de referencia. La conclusión de Railroaded lo demuestra al contemplar una historia alternativa del capitalismo: un oeste americano en el que los ferrocarriles se construyeron de forma "más barata, más eficiente y con un menor costo social y político”, una transición económica con "menos urgencias y colapsos, menos ciclos de auge y caída”. En esta historia contrafactual, el cambio económico continuó a un ritmo más lento y deliberado, una historia en la que "los ferrocarriles se construyeron conforme la demanda lo requería" (White, 2011: 516-517). Los caminos alternativos siguen siendo innumerables, incluyendo la posibilidad de que los Estados Unidos puedan haber seguido una ruta más ortodoxa para las economías del Nuevo Mundo. Cronon y White, entonces, ilustran cuán difícil es, incluso para los inicios más vigorosos, romper con las coordenadas de Chandler.

El grado en el que los tres modelos aquí descritos terminan por apoyarse en nociones de modernización podría deberse a que los tres se sustentan en la grandiosa obra de Max Weber sobre el capitalismo occidental. Como los lectores recordarán, el punto culminante de esta obra maestra era la "empresa capitalista moderna” (Weber, 1978: 1394-1395). Como una organización minuciosamente racionalizada y burocrática, la empresa moderna era superior a todas las otras formas de negocios. ${ }^{20}$ Esta imagen de la empresa moderna fue retomada con entusiasmo por Alfred Chandler, quien la con-

${ }^{20}$ Esto era porque el "tipo puramente burocrático de organización administrativa” era "capaz de alcanzar el grado más alto de eficiencia y es, en este sentido, formalmente, el medio conocido más racional para ejercer autoridad sobre los seres humanos. Es superior a cualquier otra forma en precisión, en estabilidad, en el rigor de su disciplina, en su confiabilidad [...] las necesidades de la administración de masas hacen que [la burocracia] sea completamente indispensable hoy en día. Hay que elegir, pues, entre la burocracia y el diletantismo en el campo de la administración" (Weber, 1978: 337-338). 
virtió en el pilar teórico para entender el desarrollo de las empresas estadunidenses. En efecto, en los pasajes de Economy and Society que tratan sobre burocracia, Weber está muy cerca de sonar como el heraldo de la modernización empresarial que Chandler pensó que era. ${ }^{21}$ Ciertamente, los escépticos tienen razón al ligar la historia whig de Chandler con las inspiraciones weberianas.

No obstante, Weber también recurrió a la melancolía, especialmente cuando se movió del nivel de organización al nivel social. Al describir la coerción estructural que el capitalismo ejercía sobre los individuos, Weber tendía a utilizar una cierta inflexión fatalista que Chandler ignoró por completo. Para Weber, la racionalización de la vida implicaba una pérdida distinta. Como lo explicó en The Protestant Ethic, el capitalismo fue "un cosmos inmenso en el que el individuo nace y que se le presenta, al menos como individuo, como una casa que en la práctica es inalterable y en la que tiene que vivir" (Ghosh, 2014: 300). Engendró una "disciplina infinitamente onerosa, regimentando profundamente toda la conducta de vida" (Ghosh, 2014: 300). El otro lado de este lamento, no obstante, era que el capitalismo adquirió una cualidad inexorable. Al igual que el cosmos mismo, el capitalismo era abrumador, y estaba más allá de cualquier agencia política. Desde este punto de vista, la "jaula de hierro" de Weber no implicaba tanto una crítica al capitalismo como una aseveración de que no había alternativa alguna para comprender su lógica.

Finalmente, Weber estableció una distinción profundamente normativa entre dos tipos de comportamiento capitalista: uno sobrio, firme, astuto, y otro ilícito, rapaz, irracionalmente codicioso. Weber vio todo un mundo de diferencia entre "el cálculo de rentabilidad que caracteriza la conducta empresarial racional burguesa” y "el tipo de capitalismo que vive por algunas conjeturas momentáneas, puramente políticas - contratos del gobierno, financiación de guerras, mercado negro, oportunidades de enriquecimiento y robo, ganancias y pérdidas relacionadas con el aventurismo-”. Estos “dos distintos tipos de capitalismo" estaban "tan diametralmente opuestos como pueden estarlo dos fuerzas mentales y morales” (Weber, 1994: 89). Como ejem-

\footnotetext{
${ }^{21} \mathrm{El}$ propio Chandler admitió que estaba profundamente influenciado por "el único capítulo sobre burocracia escrito por Max Weber antes de la primera Guerra Mundial” (McCraw, 2008). Cuando Chandler elogió el "enfoque continuo, frío, racional, calculador y esencialmente pragmático ante los problemas de administración” que vio en General Motors en la década de 1920, su terminología provenía justamente de Weber (Chandler, 1964: 142).
} 
plo de este segundo tipo, Weber menciona a los sospechosos habituales del capitalismo estadunidense: el intento de Henry Villard de acaparar las acciones de Northern Pacific Railroad en 1889 que ilustró el "grandioso capitalismo de ladrones (Beutekapitalismus)” de la modernidad (Weber, 1978: 1118). ${ }^{22}$ Otros ejemplos fueron J. P. Morgan, Jay Gould y Rockefeller _ “Übermenschen económicos” que estaban "más allá del bien y del mal”- (Ghosh, 2014: 315). Weber reiteró que "la estructura y el espíritu de este capitalismo ladrón difería radicalmente de la administración racional de una gran empresa capitalista ordinaria”. En cambio, era "muy similar a algunos fenómenos antiguos: las empresas enormes y rapaces en la esfera financiera y colonial, y el comercio ocasional con su mezcla de piratería y cacería de esclavos” (Weber, 1978: 1118). Recurriendo a la situación estadunidense (como hizo en varios sentidos), Weber ayudó a forjar la dicotomía entre el malvado "barón ladrón” y el noble "estadista industrial”, que después se convertiría en la tipología característica de la historia empresarial de este país. ${ }^{23}$

Weber revela que, para tener la máxima efectividad, la modernización no sólo requiere la actitud triunfalista, sino también el apoyo de la melancolía y de la normatividad. Si hacemos una lectura selectiva, podemos - al igual que Chandler - recurrir a Weber para una narrativa triunfalista de la modernización. Oponerse al triunfalismo haciendo hincapié en la pérdida y en la coerción estructural - como lo hizo Cronon - remite al modelo "melancólico” de Weber. Pero, del mismo modo, hacerlo con imprudencia conlleva el riesgo de traer políticas sin otra alternativa al capitular ante la ineluctabilidad putativa, histórica y política del capitalismo. Finalmente, las ráfagas normativas contra el aventurismo capitalista no desestabilizan por sí mismas

\footnotetext{
${ }^{22}$ Las travesuras financieras de Villard con Northern Pacific, incluyendo su reclutamiento de inversionistas alemanes, son un tema central en White (2011). El hecho de que White se adentre inconscientemente en una cámara de eco weberiana, a pesar de su profesado deseo por trascender el análisis de Weber, es un buen ejemplo de la influencia resiliente de Weber. Incidentemente, al volver a contar este episodio, White confunde a Weber el sociólogo con su padre, Weber Senior, quien viajó al oeste americano en nombre de los intereses del sistema bancario alemán, e inspiró el entendimiento inicial (y formativo) de su hijo sobre el capitalismo de los Estados Unidos. Véanse White (2011: 220) y Scaff (2011: 12).

${ }^{23}$ Véase John (2012), quien tuvo éxito en rastrear el origen del estereotipo de "barones ladrones" en los "brahamanes" de Boston (sin admitir las resonancias de este concepto en la obra de Weber), pero en nuestra opinión su lectura no dedica suficiente atención a cómo este discurso sirvió para rehabilitar el capitalismo financiero y no para desacreditarlo (siempre y cuando fuera del tipo "racional"). Para entender mejor la naturaleza egoísta y confusa de este discurso burgués en el contexto estadunidense, véase Noam Maggor (2017).
} 
el marco contextual del cambio histórico sobredeterminado. Al contrario, este tipo de ataques (popular entre los académicos americanistas) sólo reafirma una distinción ideológica entre el comportamiento capitalista legítimo y benigno y sus contrapartes ilícitas.

Sin embargo, para nuestros propósitos - la cuestión del desarrollo estadunidense desde una perspectiva comparativa - el principal problema es más profundo. Aceptar los modelos narrativos de Weber significa, al menos hasta cierto punto, seguir siendo rehén de suposiciones políticas específicas sobre el capitalismo. Sólo por mencionar algunas: por un lado, Weber atribuye el auge del capitalismo a un conjunto de actores bien definidos: la burguesía heroica y racional. Por otro lado, el capitalismo que esta clase originó resulta en un tipo de coerción estructural (la "jaula de hierro") de la que no se puede escapar y a la que no existe una alternativa: la negación de los actores. Por ende, el capitalismo es una creación histórica, pero, al mismo tiempo, está más allá del diseño político; es, a la vez, maleable y cerrado. En las manos de la burguesía empresarial, el capitalismo es un proyecto histórico creativo. Sin embargo, ante las sugerencias de que los contornos del capitalismo son susceptibles a los diseños políticos alternativos, éste se convierte en un sistema inalterable que requiere de una conformidad absoluta. Vale la pena notar lo que este gesto implica: el capitalismo moderno está establecido como el proyecto de un conjunto de actores heroicos, a los que se debe su éxito; al mismo tiempo, este proyecto de clase se ha universalizado bajo la idea de que no existe otra alternativa. La contingencia, el conflicto y la protesta política se rinden ante los resultados predeterminados. Las cuestiones de poder se funden en debates anticuados sobre carácter, eficiencia y ética. Al ser incapaces de escapar de la pesada mano del legado de Weber, estos marcos no dan cabida a una mayor diversidad de preguntas sobre desarrollo comparativo.

\section{HaCIA UNA HISTORIA POLÍtICA DEL CAPITALISMO ESTADUNIDENSE}

Hasta hace no mucho, la teoría de la modernización brindó tipologías fijas que analizaban el desarrollo comparativo en términos de formación y alianza de clases. Se ha escrito mucho sobre el impacto a largo plazo de varios alineamientos sociales mediante estas observaciones para hacer explicaciones confiables sobre trayectorias nacionales divergentes. Los académicos sugi- 
rieron que, donde fuera que las élites terratenientes retuvieran su poder, estas clases "impedían" una modernización exitosa, es decir, la "llegada” de una autoridad nacional central, mercados laborales liberales, una redistribución de tierras y una política democrática. Por lo tanto, afianzaron el modelo de "subdesarrollo" de su país o, alternativamente, lo pusieron directamente sobre el indeseable "camino prusiano". En contraste, donde fuera que la burguesía industrial ganaba poder, sus países progresaban por su camino despreocupado hacia un capitalismo liberal, se aseguraban de que se esparcieran las relaciones de mercado y garantizaban los derechos de propiedad, las leyes codificadas y una vibrante sociedad civil. Los estudios analizaron desde muy de cerca las semejanzas y las diferencias entre los dueños de las plantaciones de algodón estadunidenses, los amos del azúcar brasileños, los junkers prusianos y los nobles rusos, así como el impacto de "giros" históricos que se suelen dar por sentados, como la Guerra Civil en los Estados Unidos, la Guerra de Crimea en Rusia, las guerras napoleónicas, la revolución de 1848 en Prusia y la guerra paraguaya en Brasil.. ${ }^{24}$

Este modelo explicativo ha sufrido varios golpes directos, incluyendo una disección minuciosa por David Blackbourn y Geoff Eley, de quienes nos inspiramos nosotros. La intervención canónica de Blackbourn y Eley no sólo criticó la idea del Sonderweg alemán, sino que, yendo más allá, rechazó las nociones esquemáticas de la revolución burguesa y la normatividad liberal que estas nociones materializaban. Cuestionaron los compromisos liberales de todas las clases burguesas y la ecuación indiscutible de la democracia liberal de Europa Occidental como un remplazo para una modernización exitosa como tal. Su pregunta era: ¿cuál es la razón de atribuir papeles históricos a clases sociales altamente caracterizadas para luego criticarlas por no haber sido capaces de cumplir con estos papeles? Luego de un vistazo más minucioso, el marco entero parecía estar basado en teleologías evolutivas, suposiciones normativas y yuxtaposiciones arbitrarias (Blackbourn y Eley, 1984). ${ }^{25}$

Respecto del periodo de la preguerra, la historiografía de los Estados Unidos ha seguido completamente la guía teórica de Eley y Blackbourn. En las últimas dos décadas, las suposiciones organizativas de la historiografía de

\footnotetext{
${ }^{24}$ Véase, por supuesto, Moore (1967). Para ejemplos de cómo funcionaba esto en el contexto de la historiografía de los Estados Unidos, véanse Hahn (1990), Beckert (2001), Fox-Genovese y Genovese (1983) y Fields (1985).

${ }^{25}$ Más recientemente, la misma crítica se ha extendido de manera brillante a suposiciones no examinadas sobre la modernidad en Occidente desde la teoría poscolonial (véase Chibber, 2013).
} 
la posguerra se vinieron abajo una por una. Los dueños de las plantaciones del sur, vistos por mucho tiempo como los defensores de un régimen precapitalista "señorial", han pasado a ser considerados dinámicos, con miras al futuro y agresivamente capitalistas, al igual que el sistema laboral esclavista en el que presidieron. Lo mismo podía decirse de las élites mercantiles, pues se pensó que estaban en desacuerdo con el orden industrial creciente. Los capitalistas industriales, a su vez, resultaron ser mucho más conservadores políticamente, menos democráticos y, en general, aliados de la expansión de los regímenes de esclavitud y de trabajo coercitivo. Mientras que la literatura se volvía menos comparativa y más globalista, los académicos comenzaron a hacer hincapié en las conexiones a larga distancia que generaron patrones regionales íntimamente ligados e interrelacionados, y ya no separados y distintos. ${ }^{26}$ Los bloques claramente demarcados que conformaron la base de las historias de modernización clásicas - las unidades geográficas, la división entre Estado y mercado, el trabajo libre y esclavista, la tipología de claseahora parecen estar demasiado mezclados como para tener alguna utilidad.

La ola revisionista de académicos sobre el esclavismo y el capitalismo estadunidenses ha originado ciertas observaciones poderosas y persuasivas. Estableció la centralidad del complejo algodón-esclavitud, no sólo para la economía de los Estados Unidos en las primeras décadas del siglo XIX, sino también para la formación del comercio estadunidense, las organizaciones financieras, las prácticas empresariales y las instituciones políticas y legales. Desafió la idea de la Guerra Civil como un punto de inflexión evidente en la transición del capitalismo "moderno". No obstante, en el proceso esta corriente también debilitó el gran marco explicativo en el que los historiadores se habían basado. Este trabajo ha derribado una fundamentación teorética arraigada - lo cual no es poca cosa-, pero hasta la fecha no ha tomado su lugar un marco alternativo, lo cual deja algunas cuestiones históricas clave sin respuesta. En la ausencia de élites regionales antagónicas, por ejemplo, ¿cómo vamos a darle sentido a la antiesclavitud o a las causas primigenias de la Guerra Civil?, ¿cómo fue que un imperio esclavista, confiable, productivo e implacable fue derrotado, por quién, y por qué?, ¿la guerra en realidad marcó el triunfo de un capitalismo industrial sobre un

${ }^{26}$ Véanse Beckert (2014), Johnson (2013), Baptist (2014), Beckert y Rockman (2016), Karp (2016), Schermerhorn (2015) y Rosenthal (2018). Para más críticas en esta línea, véanse McCurry (2017), Oakes (2016), Reynolds Nelson (2015) y Mathisen (2018). 
rival político e ideológico?, ¿fue una metida de pata histórica y contingente, o quizás un no-evento, una matanza masiva y sin sentido? Dado el nuevo énfasis académico sobre los límites de la emancipación y la fácil reconciliación entre élites seccionales, ¿puede la guerra explicar por qué los Estados Unidos emergieron siguiendo un camino diferente al de cualquier otra república del Nuevo Mundo?

En este impasse se incorpora otro esfuerzo revisionista importante en la historiografía de los Estados Unidos, concretamente la fortalecida corriente académica sobre el Estado estadunidense. El nuevo consenso, considerado durante mucho tiempo lento, débil o deficiente, es que el Estado estadunidense siempre ha sido "más poderoso, capaz, tenaz, intervencionista y redistributivo de lo que habían reconocido los trabajos previos”, para recurrir a la audaz formulación de William Novak (2008). Este giro radical puede ser importante, pero no viene sin riesgos. Es muy grande la tentación de apoyarse demasiado en "el Estado" como un deus ex machina que arregla todos los acertijos en un amplio rango de temas históricos, desde la suburbanización racializada hasta la hegemonía económica global, y es fuerte también la tendencia de sobrestimar la coherencia, la capacidad y los logros del Estado. ${ }^{27}$ Sin embargo, esta corriente académica está cobrando una fuerza explicativa que se ha ido perdiendo en otros aspectos. Si los Estados Unidos de finales del siglo XIX en verdad partieron de los patrones globales predominantes, entonces esto tiene que deberse, de algún modo, a las características particulares de las instituciones del Estado estadunidense.

Identificamos aquí tres corrientes importantes en la literatura histórica contemporánea sobre el Estado estadunidense: la territorial, la institucionalista y la pragmática. Cada corriente brinda observaciones importantes, pero todas son imperfectas en algún sentido por sí solas, especialmente para nuestros propósitos comparativos. La primera, la territorial, asociada con Charles Maier, hace hincapié en los aspectos espaciales del Estado, particularmente en su habilidad para ocupar tierras, establecer y proteger sus fronteras, y administrar burocráticamente sus dominios. Maier compara los Estados Unidos con otros Estados e identifica en el primero un "Leviathan 2.0", equivalente a los que operaban en otros sitios, equipados en forma semejante para “ocupar y dominar territorio” (Maier, 2014 y 2016). Steven Hahn siguió sus pasos y puso también el auge del Estado territorial central de finales del

\footnotetext{
${ }^{27}$ Para una crítica sobre esta línea, véase Gerstle (2010).
} 
siglo XIX en el núcleo de su propia síntesis reciente. Hahn se concentra en la habilidad del gobierno federal para contener las oposiciones a la autoridad estatal central en varios frentes (secesionistas sureños, nativos americanos, mormones, obstruccionistas vendidos), y en su capacidad para "extender sus brazos” a través del Oeste Trans-Mississippi (Hahn, 2016). ${ }^{28}$ Sven Beckert es más explícito respecto de las implicaciones económicas directas de la capacidad del Estado estadunidense, particularmente el ímpetu de "capturar un enorme continente por la fuerza y luego, críticamente, integrar ese territorio administrativamente a sus estructuras de Estado" (Beckert, 2017; Bensel, 2000; Balogh, 2009).

El marco de Maier ilustra, sin duda alguna, las características clave de la formación del Estado a finales del siglo xix y principios del xx. No obstante, este marco está diseñado para explorar puntos comunes y generalizar entre casos, sin darles ningún sentido a las variaciones y las anomalías. Además, al igual que en el caso de Hahn y Beckert, esta aproximación parece preocuparse más por los límites externos de la soberanía - la integración de fronteras y periferias - que por cómo el espacio nacional en turno se volvió económicamente productivo. Ambos marcos implican que el mero acto de ocupar territorio les permitió a los Estados Unidos "estallar con potencial productivo” (Maier, 2006: 45), por ponerlo en palabras de Maier. Sin embargo, la territorialización y la administración del espacio por medio de ferrocarriles y telégrafos no fueron exclusivas de los Estados Unidos. Mientras que estos logros propulsaron el crecimiento económico, normalmente no desembocaron en una industrialización nacional - como mencionamos más arriba - . El uso de protecciones arancelarias - un aspecto importante de la economía política de la posguerra - tampoco fue exclusivo de los Estados Unidos. Los países de Latinoamérica utilizaron políticas similares con resultados muy diferentes (Coatsworth y Williamson, 2004). Pareciera que, para comprender plenamente el camino único de los Estados Unidos, se requiere un análisis de territorialidad, pero esto no es suficiente. Es necesario combinarlo con una mayor atención a las arquitecturas legales internas y a los arreglos políticos - los tendones, los músculos y los nervios políticos que permearon el espacio nacional-.

El descuido relativo de asuntos interiores en la literatura sobre territorialidad ha sido tratado recientemente por los economistas institucionalistas

${ }^{28}$ Véase también Teitelman (2020). 
Naomi Lamoreaux y John Wallis. Al buscar interrogar las complejidades internas de la economía política estadunidense, alejaron su atención del gobierno nacional para enfocarla en los estados (Lamoreaux y Wallis, 2015). Afirman que "la mayor parte del desarrollo importante que propulsó [...] la modernización económica en el siglo XIX ocurrió a nivel estatal”. ${ }^{29}$ Hacen énfasis, en particular, en la erradicación durante la era jacksoniana de privilegios legales especiales en favor de nuevas reglas impersonales en los ámbitos bancario, de infraestructura y de incorporación. Partiendo del trabajo de Douglass North, teorizan este cambio como una transición de un sistema de "acceso limitado" a uno de "acceso abierto". Proponen que la nueva sociedad de "acceso abierto eliminó la autoridad discrecional de las legislaturas del Estado”, una supuesta fuente de "corrupción sistémica”, y la remplazó con procesos impersonales que impulsaban la creación de una “economía vibrante y competitiva” (Lamoreaux y Wallis, 2015). ${ }^{30}$ Su análisis menciona este ambiente de mercado competitivo, fortificado por instituciones del Estado, para explicar el rápido desarrollo económico estadunidense.

Las características distintivas del Estado estadunidense que Lamoreaux y Wallis identifican, particularmente su énfasis en los estados, buscan separar el desarrollo económico en los Estados Unidos del de otros países. Mientras que la búsqueda de territorialidad preocupó a todos los Estados en este periodo, las instituciones políticas de los Estados Unidos a nivel subnacional fueron mucho más específicas ahí, especialmente en el contexto del Nuevo Mundo. Consecuentemente, son más aptas para explicar las particularidades del caso estadunidense (Engerman y Sokoloff, 2012). Sin embargo, la visión de la historia de Lamoreaux y Wallis es demasiado restrictiva para capturar por completo el modo en que operaban las políticas estatales. Por ejemplo, se enfocan temporalmente en la liberalización económica en las décadas de 1830 y 1840 como un giro histórico hacia una sociedad mercantil, y tratan sólo superficialmente el desarrollo histórico a largo plazo y los momentos cruciales consecuentes. Pero las constituciones estatales fueron escritas, revisadas y reescritas a lo largo del siglo. ¿Por qué privilegiar un momento sobre otros, especialmente el momento que siguió a los incumplimientos de deuda estatales después del pánico de 1837? Lamoreaux y Wallis,

\footnotetext{
${ }^{29}$ Hay una larga tradición de investigación en esta línea. Véanse, por ejemplo, Handlin (1947), Scheiber (1975), Hall Miller (1971), Goodrich (1960), Dunlavy (1994) y John (2006).

${ }^{30}$ Véase también North, Wallis y Weingast (2009).
} 
asimismo, magnifican algunas características del orden constitucional a nivel estatal -incorporación general, banca "libre” y limitaciones fiscales - a expensas de otras. Las constituciones estatales en el siglo XIX incluían realmente muchas restricciones en sus legislaturas. En un esfuerzo por promover un campo de juego más justo, prohibieron, por lo menos al principio, que se otorgaran privilegios especiales a grupos bien relacionados de inversionistas y alentaron a los legisladores a usar la legislación general más que la especial. También restringieron la inversión de los legisladores en corporaciones privadas, así como sus préstamos en créditos públicos para entidades privadas (McCurdy, 1975).

Sin embargo, ¿ estas provisiones marcaron el fin de la "manipulación de la economía con fines políticos”? Parece plausible, en cambio, ver en estas cláusulas el ejemplo de un proceso continuo para reorganizar el terreno político dentro del cual estaba enclavado el diseño de la política económica. Esto era evidente en las cláusulas constitucionales del Estado que declaraban a los ferrocarriles como common carriers y los tenían, por lo tanto, sujetos a regulación gubernamental en lo concerniente a los constantes subsidios del gobierno ( $\mathrm{y}$, de hecho, crecientes) a los proyectos de infraestructura, a las decisiones de la corte que declaraban muchos tipos de corporaciones como “empresas de servicios públicos”, así como a cientos, si no es que miles, de estatutos estatales que afectaban todos los aspectos de la vida económica (Novak, 2010: 377; Novak, 1996; Maggor, 2016). “El mercado” nunca perdió su naturaleza esencialmente política. ${ }^{31}$

Finalmente, William Novak, James Sparrow y Stephen Sawyer han propuesto una idea pragmática del Estado estadunidense. Por ser demasiado cercanos a la idea de "pluralidad exasperante" de las instituciones públicas en los Estados Unidos, rechazan la concepción del Estado estadunidense como un monolito todopoderoso. Pertinentemente, advierten sobre las inconveniencias de una noción normativa del Estado que se parece "en algo a un 'tanque' prusiano: imparable, impenetrable, autónomo, mecánicamente burocratizado, y tripulado por un funcionariado reglamentado que lo conduce por vías constantes”. En cambio, proponen un Estado “infraestructural” más realista y flexible - difuso, descentralizado, siempre incipiente y, con todo, destacablemente efectivo- (Sparrow, Novak y Sawyer, 2005). ${ }^{32}$

\footnotetext{
${ }^{31}$ En esta crítica seguimos la aproximación constitucional en la historia legal. Véase, por ejemplo, Desan (2014) y, por supuesto, Polanyi (2001).

${ }^{32}$ Para otra opinión centrada en el poder infraestructural del Estado, véase Richard R. John (2010).
} 
Sin reproducir ideas normativas sobre la burocracia del Estado, Novak, Sparrow y Sawyer dan pie a una concepción más robusta del poder público en la historia estadunidense. Develan una historia rica y densa sobre la acción gubernamental durante las décadas cruciales de la industrialización estadunidense. Destacan, en particular, los efectos de la decisión de la Suprema Corte en Munn versus Illinois - un fallo que validó la autoridad de los gobiernos estatales para regular industrias privadas y afectó el interés público-, en términos de Novak, como "la superautopista por la cual los reformadores condujeron un camión de carga de experimentos de gran alcance sobre la regulación estatal de la nueva actividad económica” (Novak, 2010). No obstante, Novak y sus coautores se mantienen al margen de las implicaciones de su propio descubrimiento conceptual. Su misma formulación confina a los actores del Estado a su papel tradicional como "reformadores" - esto es, como reactivos a lo que, de otro modo, se asume como un cambio "económico" autónomo, conducido por intereses privados-. Tal perspectiva da por sentada una distinción implícita entre acción política y acción económica, entre lo privado y lo público. Niega la participación plena de los actores políticos en la formulación y la reformulación del orden económico, más que simplemente remediar sus peores tendencias a posteriori. Esta concepción también tiende a minimizar el amplio rango de visiones políticas que contribuyeron a este proyecto estatal.

\section{El Estado desarrollista eSTAdunidense}

Volvamos a nuestra primera pregunta: ¿cómo lograron los Estados Unidos salir de la posición que tenían en la división global del trabajo durante el siglo XIX? Es decir, ¿cómo fue que esta nación no sólo aceleró su crecimiento, sino que también efectuó una transformación estructural profunda de la economía y registró tanto aumentos cuantitativos como cambios económicos cualitativos? Un marco que trate sobre este cambio de forma convincente debe ir más allá de los modelos que asocian el desarrollo, alternadamente, con la consolidación territorial (Maier), los mercados competitivos (Lamoreaux y Wallis), o una economía corporativa bien regulada (Novak, Sparrow y Sawyer). Debe brindar a las instituciones políticas un papel aún más importante que el de sólo conquistar y administrar el territorio, liberalizar la vida económica y supervisar las empresas privadas. El único 
marco que ha tratado extensivamente con estos tipos de cambios estructurales en la historia económica global surge de la literatura sobre "Estados desarrollistas". Esta literatura heterodoxa se ha basado en la experiencia de los países del este asiático como “alcanzadores” del desarrollo, en referencia a Corea, Japón, Taiwán y, más recientemente, China (Haggard, 2018). ${ }^{33}$ Al igual que los Estados Unidos durante el siglo anterior, estas naciones han logrado algo extraordinariamente difícil y raro: alteraron radicalmente sus posiciones en la división global del trabajo por la vía del desarrollo sostenible industrial y tecnológico. ¿Hay algo que podamos aprender de esta literatura que pueda aplicarse a los Estados Unidos?

En un primer vistazo, las características esenciales identificadas por esta literatura parecen estar irremediablemente en desacuerdo con las visiones convencionales de los Estados Unidos del siglo xIX que muestran a este país como la sociedad de mercado por excelencia. ${ }^{34}$ Las naciones del este asiático se desarrollaron en rechazo directo a las nociones estilizadas del sistema del mercado anglosajón. Fueron Estados (a menudo autoritarios) con fuertes burocracias que apostaban por políticas industriales intencionales. Desafiaron el estilo de liberalización del Consenso de Washington y, en cambio, protegieron y subsidiaron a sus firmas domésticas, desarrollaron “campeones nacionales” y controlaron estratégicamente la afluencia y la salida de capital extranjero. Sus ideologías de gobierno surgieron del planteamiento del último desarrollador (late developer).

No obstante, la literatura de "Estados desarrollistas" puede revitalizar esta forma más amplia en la que pensamos en nuestro desarrollo, incluyendo el caso de los Estados Unidos. Esto se debe a que el núcleo generalizable de esta literatura no reside en sus descripciones empíricas, sino en sus observaciones analíticas. La lección más instructiva de la literatura sobre "Estados desarrollistas” es la deconstrucción de las dicotomías heredadas entre política estatal y desarrollo del mercado. ${ }^{35}$ Los Estados desarrollistas exitosos no crearon espacios para que los mercados competitivos operaran con libertad, como esperarían los modelos neoclásicos o las prescripciones del institucionalismo de North. En cambio, controlaron, manejaron y manipularon los

\footnotetext{
${ }^{33}$ Para el núcleo elemental de esta literatura, véanse Johnson (1982), Amsden (1989 y 2001), Evans (1995), Wade (1990), Chang (2002) y Kohli (2004). Sobre China, véanse Ang (2016), Chen (2018) y Gabusi (2017).

${ }^{34}$ Las mejores observaciones recientes conforme a esta postura aparecen en Zakim y Kornblith (2012).

35 "El mero contraste entre la política industrial y las fuerzas del mercado es falso y probablemente ideológico" (Johnson, 1982: 48). Nosotros reforzaríamos esta aseveración y eliminaríamos el "probablemente".
} 
mercados. En lugar de rehuir de los flujos de oferta y de demanda, las instituciones de Estados desarrollistas se anidaron en ellos y los controlaron con incentivos de precios. ${ }^{36}$ Engatusaron, incitaron y empujaron los intereses privados hacia las direcciones económicamente deseadas atando "zanahorias” - subsidios, protección e incentivos - a la "disciplina” de demandas como destinar la inversión al desarrollo industrial y a las mejoras tecnológicas, cosa que los capitalistas, a pesar de su inflada reputación de "arriesgados”, hicieron de mala gana. ${ }^{37} \mathrm{El}$ desarrollo exitoso, no sólo comprendido como generador de "crecimiento" sino también de una transformación económica estructural, no requirió instituciones que "protegieran” los mercados y que los "recubrieran” (Slobodian, 2018) o "preservaran” (North y Weingast, 1989), sino que, más bien, el desarrollo surgió de instituciones que corregían y canalizaban el poder de los mercados.

La segunda lección importante de esta literatura es sobre la política del desarrollo. A pesar de que los Estados desarrollistas eran "fuertes", no eran gigantes indiferentes, monolíticos, sino, más bien, regímenes que apoyaban profundamente las coaliciones sociales orientadas al desarrollo (Evans, 1995). En ese compromiso ideológico y social absoluto con el desarrollo, seguía existiendo una disputa entre burócratas e industrialistas sobre intercambio de recursos, o sobre la estrategia, la dirección y la rapidez de la transformación económica. Las políticas desarrollistas involucraban instituciones del Estado y actores privados en confrontaciones y reajustes tensos y continuos. Los Estados desarrollistas no fueron perfectos desde el inicio en ningún lugar; al contrario, crecieron hasta superar procesos complicados de prueba y error, vencer los antagonismos políticos y crear nuevos compromisos institucionales. ${ }^{38}$ De esta literatura surge una imagen que no concuerda con la caricatura de Hayek de un Estado todopoderoso e invulnerable diri-

\footnotetext{
${ }^{36}$ Lo que Alice Amsden denominó establecer “precios relativos deliberadamente 'erróneos”” (Amsden, 1989: 13).

${ }^{37} \mathrm{La}$ descripción más incisiva viene una vez más de Amsden: los Estados desarrollistas crearon "instituciones que imponen disciplina en el comportamiento económico". La disciplina involucra "estándares de desempeño que pudieran supervisarse, que fueran de naturaleza redistributiva y que estuvieran orientados a los resultados". Esto, "por ende, transformó la ineficiencia y la venalidad asociadas con la intervención del gobierno en un bien colectivo” (Amsden, 2001: 8).

38 "Los líderes del міті [Ministerio de Comercio Internacional e Industria] y otros japoneses se dieron cuenta hasta muy tarde [la década de los sesenta] de que estaban incorporando una teoría implícita del Estado desarrollista” (Johnson, 1982: 32). "Diseñar políticas industriales efectivas [...] no involucró burócratas aislados 'que elegían ganadores', sino instituciones políticas que facilitaron la coordinación entre Estados y actores privados comprometidos con un proceso iterativo de aprendizaje" (Haggard, 2018: 91-92). China trabajó con "gradualismo y experimentalismo [...] sistemas confusos e híbridos de
} 
gido por burócratas, ni con la metafísica de Smith de una colmena de actores económicos que buscan su propio beneficio y que mágicamente obtuvieron resultados superiores. Esta literatura sugiere que el desarrollo emergió de la política de disputas institucionales.

Estas dos aportaciones - el énfasis en las instituciones como administradoras del mercado y en los debates políticos continuos sobre su operación precisa- ofrecen un rico potencial para un análisis del desarrollo en los Estados Unidos. En contraste con las narrativas weberianas que insinúan la naturaleza inexorable del desarrollo capitalista y lo alejan de los dominios del conflicto político, las observaciones de la literatura de "Estados desarrollistas” colocan a la política y la disputa justamente en el centro. Mientras que el institucionalismo de North se interesa en la disputa política hasta un punto de inflexión que da a luz a la forma "más elevada" de instituciones - sistemas de "acceso abierto" y el Estado como árbitro parsimonioso de mercados funcionales -, la literatura de "Estados desarrollistas" insiste en el conflicto continuo y la inmersión de las instituciones al crear, diseñar y controlar los mercados. Durante el siglo xIx los Estados Unidos no albergaron nada que se pareciera a las burocracias de Estado del este asiático, las cuales supervisaban y orquestaban el desarrollo. Sostenemos, no obstante, que el Estado estadunidense ganó la "capacidad institucional” para efectuar y sostener un cambio económico estructural. Es decir, ganó las capacidades de un Estado desarrollista. ${ }^{39}$

¿Por dónde podríamos comenzar a discernir las fuentes de esta capacidad institucional? ¿Dónde ganó mayor tracción el Estado estadunidense respecto de los actores privados? Aquí señalamos la estructura altamente descentralizada y traspasada del Estado. Ante el énfasis de los territorialistas en el papel del gobierno federal de integrar un mercado nacional coherente, las instituciones estadunidenses engendraron, de hecho, una desigualdad regulatoria y una variabilidad destacables. Esto no era simplemente una característica del "federalismo" como tal, sino el producto de arreglos

derechos de propiedad [...] la presencia constante de un sistema político autoritario, aunque 'fragmentado'” (Gabusi, 2017: 238).

${ }^{39}$ Como lo sugiere un reciente trabajo en este campo, lo que importa para el desarrollo puede no ser la “capacidad del Estado", como se ha entendido tradicionalmente, sino la "capacidad institucional", lo cual no necesariamente implica fuertes burocracias de Estado - véase Centeno (2017: cap. 1) - . Puesto en otras palabras, "una afirmación integrada del modelo político que sostiene al Estado desarrollista es increíblemente difícil de encontrar” (Haggard, 2018: 45). Esta opinión parece compatible con la crítica personal de Novak (2015) sobre la equivalencia entre la capacidad del Estado y la burocracia. 
políticos históricamente específicos. Como recientemente afirmó Gary Gerstle, las autoridades federales y los gobiernos estatales en los Estados Unidos no sólo difirieron en términos de escala geográfica. Los dos niveles de gobierno implementaron modos de poder fundamentalmente diferentes - casi contradictorios-. Mientras que la Constitución liberal restringía estrictamente la autoridad federal, los gobiernos estatales estaban dotados de un amplio "poder policiaco". Disfrutaron de un mandato mucho más capaz para moldear proactivamente la vida económica, un mandato que no mostró signos de erosión ni siquiera a finales del siglo XIX. Colectivistas y mayoritarios, más que liberales, los gobiernos estatales también dieron más espacio para que la política competitiva estableciera sus prioridades con menos capas de mediación entre resultados electorales y la formación de las políticas (Gerstle, 2015: 54-55 y 74-78).

El enfoque político mayoritario detrás del activismo del Estado durante las décadas críticas de la industrialización estadunidense provino con mayor fuerza (pero, por supuesto, no exclusivamente) de los electores rurales, localizados principalmente en la periferia y la semiperiferia del país. Como señalan Elizabeth Sanders y Monica Prasad, los granjeros en este periodo se movilizaron para fomentar una agenda regulatoria agresiva. Buscaron un acceso más amplio al crédito, ventajas ante las corporaciones ferroviarias y protección ante las ventajas competitivas de los monopolios, incluso a cambio de precios más altos por los productos que adquirían y consumían (Sanders, 2013; Prasad, 2013: 37). ${ }^{40}$ No exigieron un no intervencionismo liberal, sino una agenda intensamente proactiva que incluyera tributación progresiva, políticas robustas antimonopolio, protección de bancarrota, reforma bancaria y regulación empresarial (particularmente, en las tarifas de transportación ferroviaria de productos). Estas medidas se lanzaron en diferentes formas y configuraciones por medio de la legislación estatal antes de emigrar - sólo parcialmente y con gran dificultad - al nivel federal ya entrado el siglo xx. El resultado neto no fue un campo de juego parejo moldeado por una política liberal, sino un entramado denso de mercados regulados inequitativamente, superpuestos y altamente politizados. Esta "incoherencia productiva" (Hirschman) - procedimientos desconectados, experimentales, incluso erráticos, que fueron diseñados políticamente con el paso del tiempo - generó un largo catálogo de incentivos y restriccio-

\footnotetext{
${ }^{40}$ Véanse también Berk (1994) y Maggor (2016).
} 
nes (Grabel, 2017). Suponemos que, en conjunto, estas políticas obstruyeron la búsqueda de una especialización económica, canalizaron y corrigieron los flujos de capital, y alimentaron una base industrial robusta, diversa y tecnológicamente sofisticada.

El disperso patrón urbano-industrial de Michigan era representativo de la totalidad del medio oeste. A lo largo del siglo xIx, el medio oeste fomentó una industria manufacturera local en una variedad de sectores, además del procesamiento de materia prima agrícola. ${ }^{41}$ Este patrón se aceleró después de la Guerra Civil, a pesar de las rápidas mejoras en el transporte que bajaron drásticamente los costos del comercio interregional. Las industrias del medio oeste, como la vestimenta, los muebles, la impresión y la publicación, los materiales de construcción y los metales fabricados que vendían productos en mercados locales y regionales, florecieron y crecieron, a pesar de que, en el este, estaba la competencia de productores en masa que tenían acceso a los mercados nacionales y que, por lo tanto, en igualdad de condiciones, debieron haber disfrutado de una ventaja competitiva. Pero no habia igualdad de condiciones - las políticas estatales inclinaron la balanza en favor de los productores locales - y, por lo tanto, estas industrias regionales continuaron creciendo y empleando grandes números de trabajadores industriales, que, en ciertos casos, eran la mayoría de los trabajadores (Meyer, 1989).

Las mismas políticas limitaron también el lastre gravitacional de las ciudades más grandes de la región. A pesar de su crecimiento prodigioso, las mayores metrópolis del medio oeste operaron como parte de un complejo de producción territorial más amplio que incluía una red densa de ciudades pequeñas y medianas. Los empaquetadores de carne de Chicago dominaron estupendamente la industria de la carne, pero nunca la monopolizaron. Sus empaquetadores de carne trabajaron con St. Louis, Omaha, Kansas City, St. Joseph y Sioux City, sin mencionar centros más pequeños como Cedar Rapids, Waterloo, Ottumwa e Indianápolis. McCormick and Co., también de Chicago, se convirtió en la industria manufacturera más conocida de maquinaria agrícola, pero compitió en una industria diversificada con productores de Racine, Springfield, Peoria, Decatur, Rockford y South Bend. En total, cerca de la mitad de la fuerza de trabajo industrial del medio oeste, en un margen muy amplio de sectores de la industria manufacturera, labo-

\footnotetext{
${ }^{41}$ Sobre el caso de Chicago, mencionado anteriormente, véase Campante y Glaeser (2018).
} 
raba en ciudades más pequeñas. Mientras tanto, los trabajadores en las ocho ciudades más industriales (una red urbana inusualmente densa) -Chicago, Cincinnati, St. Louis, Cleveland, Milwaukee, Detroit, Louisville e Indianápolis - representaban un porcentaje estable, e incluso quizás en declive, del total de la fuerza de trabajo industrial del medio oeste. La expansión de esta geografía urbano-industrial de muchas capas - en desacuerdo con la tendencia hacia la creciente dominación de una sola gran metrópolis en otros países, especialmente en otros lugares de América - continuó hasta el siglo xx (Page y Walker, 1991; Meyer, 1989). ${ }^{42}$

Lo más destacable de la geografía económica de la región no fueron los tamaños diferenciados de sus unidades de producción o de sus locaciones descentralizadas. ${ }^{43}$ El patrón regional que observamos no simplemente mejoró, diversificó o dispersó espacialmente el arco familiar del capitalismo estadunidense; más bien, se opuso a las tendencias globales dominantes de finales del siglo xix. En lugar de una especialización regional, en el medio oeste, la industria y la agricultura se entremezclaron. En lugar de un enfoque exclusivo en la extracción de recursos y en la agricultura comercial para mercados nacionales y globales, la geografía económica del medio oeste aseguró que una fracción significativa de la acumulación tuviera un efecto benéfico regional. En lugar de empresas gigantes patrocinadas por las finanzas de la metrópolis, la región albergó una plétora de negocios medianos en un amplio margen de sectores. Si los sectores dominantes de la época -ferrocarril, acero, carbón, extracción de recursos y procesamiento de alimentos - siguieron la lógica de la Gran Especialización, la economía política del medio oeste buscó una lógica competitiva de desarrollo regional, complementariedad y diversificación económica.

No es coincidencia que, de este panorama institucional y económico, surgiera la industria que encapsuló la “segunda Gran Divergencia” como ninguna otra: la industria automotriz (Foreman-Peck, 1982; Link, en prensa).

\footnotetext{
${ }^{42}$ La obra clásica de Harriet Friedmann, siguiendo una línea similar, hizo hincapié en la "complementariedad" entre la agricultura y la industria en el caso de los Estados Unidos. Friedmann señaló que "el complejo agroalimenticio que emergió en los Estados Unidos en el siglo xix" fue único en este periodo. La dinámica intersectorial que convirtió la agricultura en "una fuente de demanda para la industria doméstica [...] [aplicó] posiblemente sólo para una sola nación-Estado", concretamente, los Estados Unidos. Sin embargo, nunca explicó por qué este patrón no emergió en otros exportadores agrícolas importantes. Véanse Friedmann y McMichael (1989), Friedmann (1978) y Friedmann y Wayne (1977). Para un trabajo en una línea similar, véase Charles Post (2011).

${ }^{43}$ El punto central de Scranton (1997) y Sabel y Zeitlin (1985 y 1997).
} 
Rara vez se aprecia que la producción automotriz masiva fue una partida abrupta de un enfoque extractivo de crecimiento dirigido por las empresas a finales del siglo xix. El automóvil emergió de los talleres de mecánicos habilidosos del medio oeste que fomentaron una visión particular del desarrollo, la cual defendía la independencia regional creciente de los circuitos de la capital del este y luchaba por una economía política basada en una participación popular tanto en producción como en consumo. En efecto, la producción automotriz masiva creció, no desde la localización de una empresa, sino desde un panorama industrial ecléctico de negocios de maquinaria enclavados profundamente en la economía política regional. El producto, el automóvil accesible, se lanzó en contra de la economía de la especialización: no beneficiaba a la extracción a gran escala ni al transporte de largas distancias. El carro, en cambio, ayudaba en los breves desplazamientos de las granjas a los mercados. El éxito del automóvil tomó a las élites financieras por sorpresa, y éstas intentaron boicotear la industria acaparando los derechos de patente sobre el carro de motor de gasolina. Este complot fue frustrado luego de un fallo legal que rechazó la concepción estrecha de los derechos de propiedad intelectual en favor de una postura de acceso abierto hacia la innovación tecnológica que impulsó la mecánica industrial (Greenleaf, 1961). No fue sino hasta la década de 1920 que el capitalismo empresarial comenzó a asimilar la producción masiva de automóviles, transformándola a ella y a sí mismo en el proceso. ${ }^{44}$

\section{CONCLUSIÓN}

Este trabajo comenzó con un acertijo: ¿cómo pudo ser posible que uno de los cambios cruciales de la historia económica global, la segunda Gran Divergencia de los Estados Unidos, haya estado volando bajo el radar del escrutinio histórico, o que al menos no haya atraído la atención académica que merece entre los historiadores? Rastreamos las razones en los patrones del pensamiento generalizado que ve el desarrollo en los Estados Unidos como algo natural y evidente, como si estuviera situado en un dominio praeter-

\footnotetext{
${ }^{44}$ Este proceso de asimilación hacia un capitalismo empresarial dejó tras de sí una fila de productores de autos que aún utilizaban el nombre del fundador original hasta mucho después de que hubiera sido removido por los inversionistas (como los Olds, Buick, Chevrolet y muchos otros, hoy olvidados). La excepción más importante de este patrón, por supuesto, fue Ford, que prevaleció a pesar de sus inversionistas. Véase Finlay Davis (1988).
} 
político. Las historias de economía trasnacional han seguido evadiendo la cuestión. La historiografía de la escuela americanista no ha podido liberarse de los patrones de la modernización que, sean de tipo whig o no, eliminan el sentido sustancial de contingencia y de contestación política de su ámbito. La literatura sobre el Estado estadunidense, en contraste, ofrece un punto de partida prometedor. La literatura sobre Estados desarrollistas en el este asiático brinda un efecto saludable de distanciamiento que valida el enfoque centrado en el Estado. Esto requiere mayor atención en los mercados como instituciones estrictamente políticas, así como en la discusión política sobre el diseño institucional de mercados. En consecuencia, creemos que el “desorden en expansión” (Novak) de arreglos políticos subnacionales en los Estados Unidos tuvo efectos en el desarrollo que, colectivamente, propulsaron la transformación económica de los Estados Unidos a finales del siglo xix y principios del xx.

Podríamos concluir dando un paso atrás e insertando estas observaciones en una genealogía de los modelos del desarrollo en los Estados Unidos, desde el mercantilismo de Alexander Hamilton por medio del "sistema estadunidense" de Henry Clay hasta el Estado desarrollista de finales del siglo XIX que mencionamos aquí, con la usurpación lenta, e incompleta, de las instituciones federales a principios del siglo xx. Esta genealogía también ofrece una concepción novedosa de las aspiraciones federales del $\mathrm{New}$ Deal y el Estado bélico de la década de los cuarenta, que controlaron grandes empresas de maneras nunca antes vistas para cumplir con metas nacionales y que comenzaron a parecerse realmente al tipo ideal de Estado desarrollista descrito en el ejemplo de Asia Oriental (Smith, 2006; Sparrow, 2011; Wilson, 2014). A partir de ahí, había sólo un pequeño paso hasta el desarrollo tecnológico de carácter defensivo engendrado por el complejo militar-industrial de la posguerra y el Estado desarrollista "en red" y moderno de los Estados Unidos, posterior a 1980, cuyos mecanismos generalizados permanecieron “ocultos” sólidamente detrás del ruido ensordecedor de los hechizos del libre mercado (Block, 2008). En esta perspectiva, las políticas de mercado y las instituciones de desarrollo han sido la regla más que la excepción, con implicaciones de alto impacto. Conforme nos acercamos a los retos del siglo XXI - “Green New Deal”, cambio climático, crecimiento equitativo-, se hace cada vez más necesario tener un mejor entendimiento de la política y de las instituciones de mayor calado, de las transformaciones económicas cualitativas en el contexto en que se encuentran los Estados Unidos. 


\section{REFERENCIAS BIBLIOGRÁFICAS}

Allen, R. C. (2014). American exceptionalism as a problem in global history. Journal of Economic History, 74(2), 309-350.

Amsden, A. H. (1989). Asia's Next Giant: South Korea and Late Industrialization. Nueva York: Oxford University Press.

Amsden, A. H. (2001). The Rise of "the Rest": Challenges to the West from Late-Industrializing Economies. Nueva York: Oxford University Press. Ang, Y. Y. (2016). How China Escaped the Poverty Trap. Ithaca: Cornell University Press.

Arrighi, G. (2010). The Long Twentieth Century: Money, Power and the Origins of Our Times. Londres: Verso.

Aston, T. H., y Philpin, C. H. E. (eds.) (1985). The Brenner Debate: Agrarian Class Structure and Economic Development in Pre-Industrial Europe. Cambridge: Cambridge University Press.

Balogh, B. (2009). A Government Out of Sight: The Mystery of National Authority in Nineteenth-Century America. Cambridge: Cambridge University Press.

Baptist, E. E. (2014). The Half Has Never Been Told: Slavery and the Making of American Capitalism. Nueva York: Basic Books.

Barbier, E. B. (2011). Scarcity and Frontiers: How Economies Have Developed through Natural Resource Exploitation. Cambridge: Cambridge University Press.

Beckert, S. (2001). The Monied Metropolis: New York City and the Consolidation of the American Bourgeoisie, 1850-1896. Cambridge: Cambridge University Press.

Beckert, S. (2014). Empire of Cotton: A Global History. Nueva York: Vintage Books.

Beckert, S. (2017). American danger: United States Empire, Eurafrica, and the territorialization of industrial capitalism, 1870-1950. American Historical Review, 122(4), 1137-1170.

Beckert, S., y Rockman, S. (eds.) (2016). Slavery's Capitalism: A New History of American Economic Development. Filadelfia: University of Pennsylvania Press.

Bensel, R. F. (2000). The Political Economy of American Industrialization, 1877-1900. Cambridge: Cambridge University Press. 
Berk, G. (1994). Alternative Tracks: The Constitution of American Industrial Order, 1865-1917. Baltimore: Johns Hopkins University Press.

Black, M. (2018). The Global Interior: Mineral Frontiers and American Power. Cambridge, Mass.: Harvard University Press.

Blackbourn, D., y Eley, G. (1984). The Peculiarities of German History: Bourgeois Society and Politics in Nineteenth-Century Germany. Oxford: Oxford University Press.

Block, F. (2008). Swimming against the current: The rise of a hidden developmental state in the United States. Politics and Society, 36(2), 1-38.

Brown, M. (ed.) (2008). Informal Empire in Latin America: Culture, Commerce and Capital. Malden, Mass.: Blackwell Publishing.

Bulmer-Thomas, V. (2014). The Economic History of Latin America since Independence, $3^{\mathrm{a}}$ ed. Cambridge: Cambridge University Press.

Campante, F., y Glaeser, E. L. (2018). Yet Another Tale of Two Cities: Buenos Aires and Chicago. Latin American Economic Review, 27(2). Recuperado de: https://link.springer.com/article/10.1007/s40503-017-0052-7

Census Reports (1902). Manufactures: States and Territories. Washington, D. C.: United States Census Bureau.

Centeno, M. A. (2017). States in the Developing World. Cambridge: Cambridge University Press.

Chandler, A. D. (1964). Strategy and Structure: Chapters in the History of the Industrial Enterprise. Londres: Massachusetts Institute of Technology. Chandler, A. D. (1977). The Visible Hand: The Managerial Revolution in American Business. Cambridge: The Belknap Press.

Chandler, A. D. (1994). Scale and Scope: The Dynamics of Industrial Capitalism. Cambridge, Mass.: Harvard University Press.

Chang, H. J. (2002). Kicking Away the Ladder: Development Strategy in Historical Perspective. Londres: Anthem.

Chen, L. (2018). Manipulating Globalization: The Influence of Bureaucrats on Business in China. Stanford: Stanford University Press.

Chibber, V. (2013). Postcolonial Theory and the Specter of Capital. Londres: Verso.

Coatsworth, J. H., y Williamson, J. G. (2004). Always protectionist? Latin American tariffs from Independence to Great Depression. Journal of Latin American Studies, 36(2), 205-232.

Cortés Conde, R. (2000). The vicissitudes of an exporting economy: Argentina, 1875-1930. En V. Bulmer-Thomas, J. H. Coatsworth y R. Cortés 
Conde (eds.), An Economic History of Twentieth-Century Latin America (vol. 1). Cambridge: Cambridge University Press.

Cronon, W. (1991). Nature's Metropolis: Chicago and the Great West. Nueva York: W. W. Norton.

Crossley, P. K. (2020). China Normal: Patterns of urbanization, industrialization, and trade on a Eurasian discursive base. Modern Asian Studies, 54, 1-37. Doi: 10.1017/S0026749X19000246

David, A. P., y Wright, G. (1997). Increasing returns and the genesis of American resource abundance. Industrial and Corporate Change, 6(2), 203-245.

Desan, C. (2014). Making Money: Coin, Currency, and the Coming of Capitalism. Oxford: Oxford University Press.

Dunlavy, C. A. (1994). Politics and Industrialization: Early Railroads in the United States and Prussia. Princeton: Princeton University Press.

Elena, E. (2016). Commodities and consumption in "Golden Age" Argentina. En Oxford Research Encyclopedia of Latin American History. Nueva York: Oxford University Press.

Engerman, S. L., y Sokoloff, K. L. (eds.) (2012). Economic Development in the Americas since 1500: Endowments and Institutions. Cambridge: Cambridge University Press.

Evans, P. B. (1995). Embedded Autonomy: States and Industrial Transformation. Princeton: Princeton University Press.

Ferguson, N. (2011). Civilization: The West and the Rest. Londres: Penguin Books.

Fields, B. J. (1985). The advent of capitalist agriculture: The new south in a bourgeois world. En T. Glymph y J. J. Kushma (eds.), Essays on the Postbellum Southern Economy. College Station, Texas: Texas A\&M University Press.

Findlay, R., y O’Rourke, K. H. (2007). Power and Plenty: Trade, War, and the World Economy in the Second Millennium. Princeton: Princeton University Press.

Fink, L. (1976). Workingmen's Democracy: The Knights of Labor and American Politics. Urbana: Chicago University Press.

Finlay Davis, D. (1988). Conspicuous Production: Automobiles and Elites in Detroit, 1899-1933. Filadelfia: Temple University Press.

Foreman-Peck, G. (1982). The American challenge of the twenties: Multinationals and the European motor industry. Journal of Economic History, 42(4), 865-881. 
Fox-Genovese, E., y Genovese, E. D. (1983). Fruits of Merchant Capital: Slavery and Bourgeois Property in the Rise and Expansion of Capitalism. Nueva York: Oxford University Press.

Friedmann, H. (1978). World market, state, and family farm: Social bases of household production in the era of wage labor. Comparative Studies in Society and History, 20(4), 545-586.

Friedmann, H., y McMichael, P. (1989). Agriculture and the state system: The rise and decline of national agricultures, 1870 to the present. Sociologia Ruralis, 29(2). Recuperado de: https://doi.org/10.1111/j.1467-9523.1989. tb00360.x

Friedmann, H., y Wayne, J. (1977). Dependency theory: A critique. Canadian Journal of Sociology, 2(4), 399-416.

Gabusi, G. (2017). “The reports of my death have been greatly exaggerated”: China and the developmental state 25 years after governing the market. Pacific Review, 30(2), 232-250.

Galambos, L. (1970). The emerging organizational synthesis in modern American history. Business History Review, 44(3), 279-290.

Gerstle, G. (2010). A state both strong and weak. American Historical Review, 115(3), 779-785.

Gerstle, G. (2015). Liberty and Coercion: The Paradox of American Government from the Founding to the Present. Princeton: Princeton University Press.

Ghosh, P. (2014). Max Weber and the Protestant Ethic: Twin Histories. Oxford: Oxford University Press.

Glaeser, E. L., Di Tella, R., y Llach, L. (2008). Introduction to Argentine exceptionalism. Latin American Economic Review, 27(1). Recuperado de: https://doi.org/10.1007/s40503-017-0055-4

Goodrich, C. (1960). Government Promotion of American Canals and Railroads, 1800-1890. Nueva York: Columbia University Press.

Goodwyn, L. (1976). Democratic Promise: The Populist Moment in America. Nueva York: Oxford University Press.

Grabel, I. (2017). When Things Don't Fall Apart: Global Financial Governance and Developmental Finance in an Age of Productive Incoherence. Cambridge, Mass.: The Miт Press.

Greenleaf, W. (1961). Monopoly on Wheels: Henry Ford and the Selden Automobile Patent. Detroit: Wayne State University Press.

Gutman, H. G. (1976). Work, Culture, and Society in Industrializing 
America: Essays in American Working-Class and Social History. Nueva York: Blackwell.

Haggard, S. (2018). Developmental States. Cambridge: Cambridge University Press. Hahn, S. (1990). Class and state in postemancipation societies: Southern planters in comparative perspective. American Historical Review, 95(1), 75-98. Hahn, S. (2016). A Nation without Borders: The United States and Its World in an Age of Civil Wars, 1830-1910. Nueva York: Penguin Books.

Hall Miller, G. (1971). Railroads and the Granger Laws. Madison: University of Wisconsin Press.

Handlin, O. (1947). Commonwealth: A Study of the Role of Government in the American Economy. Massachusetts, 1774-1861. Nueva York: New York University Press.

Hobsbawm, E. J. (1968). Industry and Empire: The Making of Modern English Society, 1750 to the Present Day. Nueva York: Pantheon Books. Hofstadter, R. (1948). The American Political Tradition and the Men Who Made It. Nueva York: Alfred A. Knopf.

Hopkins, A. G. (2018). American Empire: A Global History. Princeton: Princeton University Press.

John, R. R. (2006). Ruling Passions: Political Economy in the NineteenthCentury America. University Park, Pensilvania: Pennsylvania State University Press.

John, R. R. (2010). Network Nation: Inventing American Telecommunications. Cambridge, Mass.: Belknap Press of Harvard University Press.

John, R. R. (2012). Robber barons redux: Antimonopoly reconsidered. Enterprise and Society, 13(1), 1-38.

Johnson, C. (1982). MITI and the Japanese Miracle: The Growth of Industrial Policy, 1925-1975. Stanford: Stanford University Press.

Johnson, W. (2013). River of Dark Dreams: Slavery and Empire in the Cotton Kingdom. Cambridge, Mass.: Belknap Press of Harvard University Press. Josephson, M. (1934). The Robber Barons: The Great American Capitalists, 1861-1901. Nueva York: Harcourt.

Karp, M. (2016). This Vast Southern Empire: Slaveholders at the Helm of American Foreign Policy. Cambridge, Mass.: Harvard University Press. Kramer, P. A. (2011). Power and connection: Imperial histories of the United States in the world. American Historical Review, 116(5). 1348-1391.

Krippner, G. (2017). Polanyi for the Age of Trump. Critical Historical Studies, 4(2), 243-254. 
Kohli, A. (2004). State-Directed Development: Political Power and Industrialization in the Global Periphery. Cambridge: Cambridge University Press. Lamoreaux, N. R., y Wallis, J. J. (2015). States, Not Nation: The Sources of Political and Economic Development in the Early United States (working paper). New Haven: Universidad de Yale. Recuperado de: https://economics.yale.edu/sites/default/files/files/Faculty/Lamoreaux/ lamoreaux-wallis-2015.pdf

Landes, D. S. (1969). The Unbound Prometheus: Technological Change and Industrial Development in Western Europe from 1750 to the Present. Cambridge: Cambridge University Press.

Landes, D. S. (1998). The Wealth and Poverty of Nations: Why Some Are so Rich and Some so Poor. Nueva York: W. W. Norton.

Lewis, C. M. (1983). British Railways in Argentina, 1857-1914: A Case Study of Foreign Investment. Londres: Bloomsbury.

Lewis, R. D. (2008). Chicago Made: Factory Networks in the Industrial Metropolis. Chicago: University of Chicago Press.

Link, S. (en prensa). America's Antagonists: Making Soviet and Nazi Fordism in the Global Thirties. Princeton: Princeton University Press.

Maier, C. S. (2006). Transformations of territoriality, 1600-2000. En G. Budde, S. Conrad y O. Janz (eds.), Transnationale Geschichte: Themen, Tendenzen und Theorien. Gotinga: Vandenhoeck \& Ruprecht.

Maier, C. S. (2014). Leviathan 2.0: Inventing Modern Statehood. Cambridge, Mass.: Belknap Press of Harvard University Press.

Maier, C. S. (2016). Once Within Borders: Territories of Power, Wealth, and Belonging since 1500. Cambridge, Mass.: Harvard University Press.

Maggor, N. (2016). To 'coddle and caress these great capitalists': Eastern money and the politics of market integration in the American West. American Historical Review, 121(1), 55-84.

Maggor, N. (2017). Brabmin Capitalism: Frontiers of Wealth and Populism in America's First Gilded Age. Cambridge, Mass.: Harvard University Press.

Mathisen, E. (2018). The second slavery, capitalism, and emancipation in Civil War America. Journal of the Civil War Era, 8(4), 677-699.

Mazzucato, M. (2013). The Entrepreneurial State: Debunking Public vs. Private Sector Myths. Londres: Anthem Press.

McCraw, T. K. (2008). Alfred Chandler: His vision and achievement. Business History Review, 82(2), 207-226. 
McCurdy, C. W. (1975). Justice field and the jurisprudence of government-business relations: Some parameters of laissez-faire constitutionalism, 1863-1897. Journal of American History, 61(4), 970-1005.

McCurry, S. (2017). Plunder of black life. Times Literary Supplement. Recuperado de: https://www.the-tls.co.uk/articles/slavery-economics/

Meyer, D. R. (1989). Midwestern industrialization and the American manufacturing belt in the nineteenth century. Journal of Economic History, 49(4), 921-937.

Mokyr, J. (ed.) (1993). The British Industrial Revolution: An Economic Perspective. Boulder: Westview Press.

Mokyr, J. (2017). A Culture of Growth: The Origins of the Modern Economy. Princeton: Princeton University Press.

Montgomery, D. (1987). The Fall of the House of Labor: The Workplace, The State and American Labor Activism, 1865-1925. Cambridge: Cambridge University Press.

Moore, B. (1967). Social Origins of Dictatorship and Democracy: Lord and Peasant in the Making of the Modern World. Boston: Beacon Press.

North, D. C., y Weingast, B. R. (1989). Constitutions and commitment: The evolution of institutions governing public choice in seventeenth-century England. Journal of Economic History, 49(4), 803-832.

North, D. D., Wallis, J. J., y Weingast, B. R. (2009). Violence and Social Orders: A Conceptual Framework for Interpreting Recorded Human History. Cambridge: NBER.

Novak, W. J. (1996). The People's Welfare: Law and Regulation in Nineteenth-Century America. Chapel Hill: The University of North Carolina Press.

Novak, W. J. (2008). The myth of the "weak" American state. American Historical Review, 113(3), 752-772.

Novak, W. J. (2010). Law and the Social Control of American Capitalism. Emory Law Journal, 60(2), 377-405.

Novak, W. J. (2015). Beyond Max Weber: The need for a democratic (not aristocratic) theory of the modern state. Tocqueville Review/La Revue Tocqueville, 36(1), 43-91.

O’Rourke, K. H., y Williamson, J. G. (eds.) (2017). The Spread of Modern Industry to the Periphery since 1871. Oxford: Oxford University Press.

Oakes, J. (2016). Capitalism and slavery and the Civil War. International Labor and Working Class History, 89, 195-220. 
Ogle, V. (2017). Archipielago capitalism: Tax havens, offshore money, and the state, 1950s-1970s. American Historical Review, 122(5), 1431-1458. Osterhammel, J. (2014). The Transformation of the World: A Global History of the Nineteenth Century, trad. de Patrick Camiller. Princeton: Princeton University Press.

Page, B., y Walker, R. (1991). From settlement to Fordism: The agro-industrial revolution in the American Midwest. Economic Geography, 67(4), 281-315.

Paolera, G. della, y Taylor, A. M. (eds.) (2003). A New Economic History of Argentina. Cambridge: Cambridge University Press.

Pineda, Y. (2009). Industrial Development in a Frontier Economy: The Industrialization of Argentina, 1890-1930. Stanford: Stanford University Press.

Polanyi, K. (2001). The Great Transformation: The Political and Economic Origins of Our Time. Boston: Beacon Press. [Versión en español: (2017). La gran transformación. Los orígenes politicos y económicos de nuestro tiempo. México: Fondo de Cultura Económica.]

Pomeranz, K. (2001). The Great Divergence: China, Europe, and the Making of the Modern World Economy. Princeton: Princeton University Press. Post, C. (2011). The American Road to Capitalism: Studies in ClassStructure, Economic Development, and Political Conflict, 1620-1877. Leiden: ProQuest.

Prasad, M. (2013). The Land of Too Much: American Abundance and the Paradox of Poverty. Cambridge, Mass.: Harvard University Press.

Reynolds, L. G. (1985). Economic Growth in the Third World, 1850-1980. New Haven: Yale University Press.

Reynolds Nelson, S. (2015). Who put their capitalism in my slavery? Journal of the Civil War Era, 5(2), 289-310.

Rocchi, F. (2006). Chimneys in the Desert: Industrialization in Argentina during the Export Boom Years, 1870-1930. Stanford: Stanford University Press.

Rodgers, D. T. (1977). Tradition, modernity, and the American industrial worker: Reflections and critique. Journal of Interdisciplinary History, 7(4), 655-681.

Rodgers, D. (1998). Exceptionalism. En A. Molho y G. S. Wood (eds.), Imagined Histories: American Historians Interpret the Past. Princeton: Princeton University Press. 
Rosenthal, C. (2018). Accounting for Slavery: Masters and Management. Cambridge, Mass.: Cambridge University Press.

Rostow, W. W. (1960). The Stages of Economic Growth: A Non-Communist Manifesto. Cambridge: Cambridge University Press.

Sabel, C., y Zeitlin, J. (1985). Historical alternatives to mass production: Politics, markets and technology in nineteenth-century industrialization. Past and Present, (108), 133-176.

Sabel, C., y Zeitlin, J. (eds.) (1997). World of Possibilities: Flexibility and Mass Production in Western Industrialization. Nueva York: Cambridge University Press.

Sachs, J. D., y Warner, A. M. (2001). The curse of natural resources. European Economic Review, 45(4-6), 827-838.

Sanders, E. (2013). Roots of Reform: Farmers, Workers, and the American State, 1877-1917. Chicago: University of Chicago Press.

Scaff, L. A. (2011). Max Weber in America. Princeton: Princeton University Press. Scheiber, H. N. (1975). Federalism and the American economic order, 17891910. Law and Society Review, 10(1), 57-118.

Schermerhorn, C. (2015). The Business of Slavery and the Rise of American Capitalism, 1815-1860. New Haven: Yale University Press.

Scranton, P. (1997). Endless Novelty: Specialty Production and American Industrialization, 1865-1925. Princeton: Princeton University Press.

Sklar, M. J. (1992). Studying American political development in the progressive era. En The United States as a Developing Country: Studies in U.S. History in the Progressive Era and the 1920s. Cambridge: Cambridge University Press.

Slobodian, Q. (2018). Globalists: The End of Empire and the Birth of Neoliberalism. Cambridge, Mass.: Harvard University Press.

Smith, J. S. (2006). Building New Deal Liberalism: The Political Economy of Public Works, 1933-1956. Cambridge: Cambridge University Press.

Sparrow, J. T. (2011). Warfare State: World War II Americans and the Age of Big Government. Nueva York: Oxford University Press.

Sparrow, J. T., Novak, W. J., y Sawyer, S. (eds.) (2005). Boundaries of the State in the US History. Chicago: The University of Chicago Press.

Teitelman, E. (2020). The properties of capitalism: Industrial enclosures in the south and west after the American Civil War. Journal of American History, 106(4), 879-900.

Topik, S. C., y Wells, A. (2014). Global Markets Transformed: 1870-1945. Cambridge, Mass.: Harvard University Press. 
Tyrrell, I. (1991). American exceptionalism in an age of international history. American Historical Review, 96(4), 1031-1055.

Vogel, S. K. (2018). Marketcraft: How Governments Make Markets Work. Nueva York: Oxford University Press.

Wade, R. (1990). Governing the Market: Economic Theory and the Role of Government in East Asian Industrialization. Princeton: Princeton University Press.

Wallerstein, I. M. (1974). The Modern World-System. Nueva York: University of California Press.

Weber, M. (1978). Economy and Society: An Outline of Interpretive Sociology, trad. y ed. de Guenther Roth y Claus Wittich. Berkeley: University of California Press.

Weber, M. (1994). Suffrage and democracy in Germany. En P. Lassman y R. Speirs (eds.), Weber: Political Writings. Cambridge: Cambridge University Press.

White, R. (2011). Railroaded: The Transcontinentals and the Making of Modern America. Nueva York: W. W. Norton.

Wiebe, R. H. (1967). The Search for Order, 1877-1920. Nueva York: Hill \& Wang.

Williams, E. E. (1944). Capitalism and Slavery. Chapel Hill: University of North Carolina Press.

Wilson, M. (2014). Destructive Creation: American Business and the Winning of World War II. Filadelfia: University of Pennsylvania Press. Wright, G. (1990). The origins of American industrial success, 1879-1940. American Economic Review, 80(4), 651-668.

Wright, G., y Czelusta, J. (2004). The Myth of the Resource Curse. Challenge, 47(2), 6-38.

Zakim, M., y Kornblith, G. J. (eds.) (2012). Capitalism Takes Command: The Social Transformation of Nineteenth-Century America. Chicago: The University of Chicago Press. 